\title{
How Consumers Justify Their Unethical Behavior: The Role of Moral Recognition Strategies (Moral Rationalization, and Decoupling), Complemented by Culture, on the Purchase of Counterfeits in Pakistan
}

\author{
Usman Tanveer \\ Research Scholar, Karachi University Business School \\ University of Karachi, Pakistan \\ E-mail: usmantanveer0334@gmail.com \\ Dr. Danish Ahmed Siddiqui \\ Associate Professor, Karachi University Business School \\ University of Karachi, Pakistan \\ E-mail: daanish79@hotmail.com
}

Received: December 21, 2020

Accepted: January 28, 2021 Published: February 10, 2021

doi:10.5296/ijim.v6i1.18312 URL: https://doi.org/10.5296/ijim.v6i1.18312

\begin{abstract}
Moral recognition, is defined as a person's description of a condition as ethical dilemma. However, people will not always interpret situations as ethical problems in the same way with the same force under all circumstances. The literature suggests that when two conditions of acceptance of ethics (moral rationalization and decoupling) are met, people will define the situation as a ethical problem differently. In the moral system, people use it to turn immoral acts into less immoral acts. Therefore, it allows them to violate ethical standards while maintaining a certain standard of conduct such as buying counterfeit goods because of their low prices. Here, consumers are more likely to make a profit by rearranging their actions for less ethical, which means seeking appropriate ethical reasons (including ethical justification, non-professional language, beneficial comparisons, migration of responsibilities, distribution of responsibility, distortion of results, prosecution; (Bandura et al., 1996), to coordinate adjustments and conditions, and to reach a judgment. Moral decoupling is defined as a
\end{abstract}




\section{Macrothink}

psychological process chosen to prevent misconduct, in which one separates the judgment of performance from judgments of morality (Bhattacharjee et al., 2013). When people use this strategy, they focus on social benefits (e.g., image, use of status, etc.) as well as economic benefits (e.g., visual fashion content, physical appearance, performance, scarcity, etc. Chen et. al. (2018) linked these two strategies in an empirical assessment to explore the effect of dimensions of moral recognition (moral rationalization and moral decoupling) on counterfeit purchases mediated by moral judgment and perceived benefits respectively. We modified the Chen model with the complementary effect of materialistic culture in this relationship. We argue that moral recognition firstly affects counterfeit purchase (CP) through Moral rationalization, and then through moral judgment in a two-step mediation. Secondly, through moral decoupling and further through perceived benefits. Thirdly, directly affecting CP complemented by materialistic culture as a moderator. Empirical validity was established by conducting a survey employing a close-ended questionnaire. Data was collected from 230 consumers and analyzed using confirmatory factor analysis and structured equation modeling. The results suggested that moral recognition seems to limit purchase intention (PI) directly. Similarly, it neutralizes to Moral Rationalization (MR), and Decoupling (MD) behaviors. Moreover, MR tends to positively affect PI both directly, and well as indirectly through moral judgment (MJ). Similarly, MD also has a direct and positive effect on PI, as well as perceived benefits (PB), however, PB and PI relationship was not substantiated. Hence, MR seems to negatively affect PI through MD, as well as through MR and MJ as a first and second-order mediator. Lastly, materialism seems to promote the counterfeit purchase, at the same time positively complement the effect of MR on PI, in a way that MR would have a more pronounced effect on PI in case of the higher materialistic consumer.

Keywords: Moral recognition, Moral decoupling, Counterfeit purchase intentions, Moral reasoning, Moral rationalization, Materialism, Perceived benefits, Moderating effect, Moral Judgment 


\section{Introduction}

\subsection{Background of Study}

Morality is defined as principles or norms that are independent and autonomous from group conventions given the generalizable nature of justice, fairness, and equality, for example (Rutland et al., 2010, p. 281). In business segment each business has a type of virtues and moral for shoppers. As a result of customer supplies, shoppers have an extremely important role in running this business. Usually, after buying goods, shoppers obey certain moralities.

A moral evaluation of the degree to which certain conduct or course of action is moral or immoral is defined as the individual's personal study. Moreover, moral reasoning is viewed as a very deliberate method of approaching a radical sequence of steps in order to make an ethical conclusion once a radical sequence is made. Taking this viewpoint, that moral judgments of consumers typically accept varying situations, which entail entirely different choices in terms of forgery (Bandura, 1991). Burglar of brand names has risen over the last twenty years by more than ten thousand percent and costs are over \$200 billion a year for U.S. producers (International Alliance for Counterfeiting, 2012). Counterfeit commodities which incorporate any illegal result of merchandise, are developing in prevalence (particularly luxury brands) because of constrained creation opportunity and the wellspring of consumer request. Initial research on counterfeit purchases have shown that luxury brands manufacture fake purchases by customers to satisfy their social assimilation needs (Han, Nunes, \& Drèze, 2010; Wilcox, Hyeong, \& subunit, 2009). Moreover, counterfeit literature shows customers purchase counterfeit goods for sending a positive signal both to others and to them (Bodner \& Prelec 2002; Wilcox, Hyeong, \& subunit, 2009). Although research in each of these areas offers a clear insight into how luxury products and counterfeits are interpreted by shop people, some questions remain unreciprocated for the real integration of these sources. In the view of the buyers, counterfeiting is always misleading or irritating (Grossman \& Shapiro, 1988).

It is surprising that the review has seldom discussed the impact between ethics and counterfeit practice in a morally shifting environment. At long last, this is entirely easily proven wrong issue that's why the shoppers disregarded and dismissed the morals and virtues for buying and seeking after of their preferred brands and merchandise. In addition, there is likewise need to test this issue exactly.

This is an interesting study of consumer behavior with significant consequences for falsified consumer behavior, among the numerous techniques used by shoppers. Similarly, it is sometimes argued that many shoppers are tempted to buy fictitious products as a result of shopping for fictitious products falling to reasonable dishonesty intervals and enabling them to unbundle rank and quality characteristics of a single standing while not paying high value (Bian \& Mutinho, 2009). Truth be told, there is solid need to watch that is these genuine purchasers follow system of moral purposes behind procuring of their brands climate in sham manner or counterfeit way. In Pakistani setting there is no observational study discovered which has tried this marvel through quantitative methodological procedures and moreover, with the assistance of survey apparatus. 


\subsection{Problem Statement}

Counterfeiting - the process of producing and selling any unauthorized product that infringes upon intellectual property rights (brand names, patents, trademarks, or copyrights) (Chaudhry \& Walsh, 1996; Kapferer, 1995) - is a rapidly growing, international problem. Counterfeit consumption has become a notable moral issue worldwide in recent years. The use of counterfeits of luxury brands has become a Phenomenon in Pakistan in recent years. Since they are the most significant facilitator for consumers to reach luxury consuming Products.

Counterfeiting is that any unauthorized product infringing on property rights (names, trademarks, logo, copyright) may be an enhancement of an international disadvantage in its manufacturing and trade process (Chaudhry \& Walsh, 1996). In the current situation, shoppers have a flexible and even sensible kind of action and decision-making. Most of them don't follow the moral philosophy of their favorite product. Furthermore, it was found in many studies that the moral rationale of the creation of the products was less pursued (Baumeister \& Newman, 1994; Bandura, 1999; Bandura et al., 1996). Furthermore, shoppers tend to have a history of moral thought to help access the desired commodity in the face of counterfeiting (Gentry \& coll, 2001). Shoppers follow entirely different strategies, love conformed to social expectations, flattery, self-promotion (Escalas \& Bettman, 2003) or deceptive behavior (Mazar, Amir, \& Ariely, 2008).

Innovative scientific goods supplied via the web and online support to the selling of counterfeit products via the Internet, particularly commercially counterfeit luxuries. Expert luxury manufacturers, for example, used the platforms of "daraz," "Alibaba" and "Aliexpress" in the Pakistan to sell products by reducing risks of advertising and inquiry. Black trade's undesired effects have introduced strict rules and regulations against counterfeiting to Pakistan's government. When the additional Pakistani population became apparent, they were busy counterfeiting, they stated that both are expelled from the country (conscious of their standard and morality). And secondly, that they will think of the lighter facet of the entire legislation, in contrast to strict regulation, to assist Pakistan in the form of fake packaging of a counterfeit product and in particular the third category quality associated with it as offence. In general, discourage strategies such as "the buying of counterfeit products from the pocket book is taken into account as a fraud." Or "Buy a Cartier copy, get a true listing." However, counterfeit and its shopping for activities still thrive and are customarily debatable.

What's more, a must find out from that analysis is the fact that, if it's about behavioral shopping and this additional analytical skill, the moral dilemma is ignored for the Pakistani shopper. Regardless of what appears to be realistic insight into this "falsification" consumers are involved in counterfeit goods, despite all. In the same strategy, producers have been proposed to think about making the same product as their imitation goods to customers.

In literature, the moral significance of purchasing expensive counterfeit products has been talked about, and the extent of effect concerns the general outcome of the purchase (Tsalikis et al., 2008). Therefore, the higher the number of people living in a scenario or the higher the failure, the greater the perceived effect (Brass et al., 1998). In general, the literature indicates 
that the upper an Individual is conscious of the impact of the action, and that the relationship between the person is certainly ethically perplexing in terms of morality and awareness (Jones, 1991; Tsalikis et al., 2008). The related literature indicates, even in the light of moral acceptance and thus severity of moral issues, that a private person doesn't necessarily have to know an ethical dilemma all told (Brass et al., 1998). The systematic analysis of the reasons why consumers purchase counterfeit goods, and the identification of morals play a significant part in counterfeit consumption (Wilcox et al., 2009). Monetary feelings, the status quo, the quest for newness, the knowledge that want to impress people have also been included as factors of counterfeit consumption.

In addition, previous studies have combined the option of knowingly receiving counterfeit goods with several factors which are divided into four groups by (Eisend \& Schuchert-Guler, 2006). In addition to attitudes towards counterfeiting, the primary class, called 'individual,' includes demographic and psychographic variables. Previous studies have shown that customers who buy fake goods hold low rank and have a more favorable attitude to counterfeiting (Bloch, Bush, and campbell, 1993) (Penz \& Stottinger, 2005). This class is jointly defined as an empirical connection between consumer perceptions about counterfeit goods and their purchasing behavior (for example, Gentry, Putrevu, \& Shultz, 2006).

The second class focuses on the aspects of products, love value, individuality and comfort. Not surprisingly, the purchasing incentive of customers for the fake product is the value of the actual brand reciprocally (Albers Miller, 1999). The 3rd and 4th grades deal with the social and cultural sense in which the counterfeit buying process starts, beginning with culture standards (Lai \& Zaichkowsky, 1999).

\subsection{Gap Analysis}

Analysts' portrayals of profound quality have stayed consistent, as for its solid negative relationship with fake buy goal (Chen et al., 2015; Cronan \& Al-Rafee, 2007; Fernandes, 2013; Kim \& Johnson, 2014; Logsdon et al., 1994; Michaelidou \& Christodou-lides, 2011; Simpson et al., 1994; Tan, 2002; Wang et al., 2005, 2014). In other words, buyers are less inclined to buy fake products when they know that such conduct is ethically off-base (Cordell et al., 1996; Penz \& Stottinger, 2005; Tan, 2002). Morality has overall negative implications for fake utilization, nonetheless, questions can be raised concerning whether this is a well known fact, or if the outcomes are limited by a thin reason that purchasers' ethical decisions are unchangeable. A moral judgment is characterized as a person's very own assessment of how much some conduct or game-plan is moral or untrustworthy (Kim \& Johnson, 2014; Sparks \& Pan, 2010). Further, moral thinking is characterized as a cognizant cycle of arriving at an ethical judgment after a careful grouping of steps, for example, looking for proof, gauging proof, organizing proof with speculations, and arriving at a choice (Bargh, 1994; Galotti, 1989). Taking this viewpoint, buyers' ethical decisions regularly depend on shifting conditions, calling for various choices about fake buying (Ban-dura, 1991).

Furthermore, drawing on moral disengagement theory, past examination has indicated that people are persuaded to justify their shameless practices through blame evasion (Bandura, 1999; Bandura et al., 1996; Bhattacharjee et al., 2013; Tsang, 2002). Few researchers have 
thought about the impact of moral rationalization (e.g., discovering legitimizations for fake buying) with regards to fakes (Eisend \& Schuchert-Gu“ler, 2006), no exact proof has been introduced.

In such manner, Chen et al. (2018) in their observational evaluation, connected two moral thinking methodologies: (1) moral rationalization, the way toward remaking immoral activities into less shameless activities (Baumeister \& Newman, 1994; Bandura, 1999; Bandura et al., 1996); and (2) moral decoupling, a psycho-legitimate partition measure, in which people specifically separate judgments of performance from judgments of morality (Bhattacharjee et al., 2013). A large portion of the exploration concentrates on the previous (Aquino et al., 2007; Baumeister \& Newman, 1994; McAlister et al., 2006; Shu et al., 2011), while giving little consideration to the last mentioned, no past investigation attempts to investigate the likelihood that these two cycles may work at the same time. They investigated the impact of moral rationalization and ethical decoupling measurements of moral recognition, on fake buys interceded by moral judgment and perceived benefits individually.

However, they didn't focus on the cultural aspect of moral recognition and counterfeit purchase. The relationship identified can be further conditioned based on consumers' cultural orientation. In Particular, materialistic culture is often linked with hedonistic buying and unethical purchase. In response to this, we further modified Chen model with the complementary effect of materialistic culture in this relationship. We argue that the effect of moral recognition, on counterfeit purchases is stronger in materialistic consumers.

This is a novel attempt as no previous study attempted to investigate the culture aspect of moral recognition and counterfeit purchase in an interactive structural framework. Moreover, no previous study offered to explain this in Pakistani context. Hence, this would further extend the research frontier and provided a much-needed generalization of unethical purchase literature.

\subsection{Research Objectives}

Morality has been extensively debated in the current literature as being closely associated with a reduced procurement in the case of luxury counterfeit products. But based on the principle of moral disengagement, we argue that individuals are motivated to justify their unethical actions by evading guilt. This study shows that the consumer's desire to gain falsified luxury relies on two forms of moral thinking: morality and moral decoupling. Each strategy increases the purchasing intent but also moral judgement and perceived profit, according to empirical findings. Implications are discussed for scientists and administrators.

Previous research indicates contradictory and often inconsistent results as to whether materialism is correlated with intention of purchasing counterfeit products, either positively or negatively. These contradictions are overcome with an analysis of the interactions between the three variables previously ignored: chance of embarrassment, false detectability and product conspicuity. Second, the possibility of humiliation mediates the association between materialism and false buying intentions. Materialism predicts negative buying intentions as mediated by risk of humiliation in particular. Second, this relationship only applies if the 
falsification is easily observable. Instead materialism results in good purchasing intentions if it's not quickly found. Third, if the substance is not strongly noticeable, these beneficial results may be reversed. This study has significant effects for retailers, suppliers and researchers, and helps to better understand the past of false sales.

We described moral recognition first and the evidence supported jointly tests this analysis. Use the hypothesis together to analyze this analysis to classify a seller about the shopping for a counterfeit product in the previous quantitative study. We argue that moral recognition firstly affects counterfeit purchase (CP) through Moral rationalization, and then through moral judgment in a two-step mediation. Secondly, through moral decoupling and further through perceived benefits. Thirdly, directly affecting CP complemented by materialistic culture as a moderator.

\subsection{Research Question}

1) What is the effect of the consumer moral reasoning strategy influence on consumer pursuit of counterfeits?

2) What is the impact of materialism as a moderator on moral recognition and purchase intentions?

\subsection{Significance of Study}

For the purposed of the literary industry, it is clear that there are still areas not explored in the field and, thus, this report is of interest for covering those areas which have jointly contributed to the literature, by means of the findings of this analysis. In the cooperative approach some previous studies have overlooked such variables, so this research has value jointly to consider the influence of ethical approaches on the detection of counterfeit goods. In addition, it is important for policymakers to track and coordinate such types of brands together in this report. Finally, the primary feedback of this study also supported future researchers in the field of domain. Likewise, this study additionally has noteworthiness for investigation of impact of moral recognition on purchase intentions for counterfeit just as this study will be useful for assessment of the impact of moral rationalization on customer intentions for counterfeits.

\section{Conceptual Framework and Hypotheses}

Even with repetition, consumers often prioritize behavioral choices through direct entry of a suitable product (Gentry et al., 2001). This study examined two types of behavioral thinking patterns, behavioral rationalization and behavioral decoupling, both of which are used by clients to help justify the illicit purchase of purchases when faced with a behavioral problem (Haidt, 2001; Kohlberg, 1969). Behavioral thinking processes were considered to affect the impact of a purchase with a view to good behavior and tangible benefits. The diagram illustrates the visual representations of the research studied in this study.

\subsection{Purchase Intentions}

As far as shoppers are concerned, brand equity means that shoppers build a connection 
between brand equities and name as value added to the products. Although the value added will be diverse in nature, its key components are necessary to evaluate the purpose and actions of transactions entirely (Netemeyer et al., 2004, p. 210). The explanation behind it is that the consumer wants to buy a product or service if he or she is able. Since the boss wants to gain, this may be the most reflective of the loyalty of names (Aaker, 1991). When shoppers buy the counterfeit product, they assume that the status of the original product is a bit like each other due to the physical appearance. Consumers who have significant financial benefits and are willing to obtain their original luxury brands do not want to use counterfeits because they feel that buying original products is appreciation, which means embracing the business and that falsifications are perceived as being below their worth (Nia \& Zaichkowsky, 2000). Yoo and Lee (2009) suggest that past acquisition activity has the greatest effect on luxury fashion counterfeit use. When a consumer has shopping experience for a counterfeit product, this approach can become a norm. Luxury brands are striving to boost quality so that counterfeiting is not easily tracked. So as to discourage counterfeit goods. But the key challenge, by encouraging a challenge like a crime, is to affect the tightened dimension (Yeo $\&$ Lee, 2009). When consumers have a negative opinion of the counterfeit products law, this new fact has a direct impact on their decisions. There might be a feeling of quilt and guilt regarding knowledge, which would avoid shoppers' desire to acquire and consume counterfeit products. While many shoppers are in the way of the unlawful act alluded to above, their interest in counterfeit products still remains. Additionally, the empirical study of this type of client angle was performed (Cordell et al., 1996). Based on the research done by Walker in 1977, people are happy with their unethical behaviors and appear to break the rules. The most motivating incentive of the intent to obtain counterfeit products might be Price, because shopper has nothing to do with the Moral Face of the case, and they must take pleasure economically compared to the real ones (Tom et al., 1998; Ernest Bloch et al., 1993; Albers-Miller, 1999; National Guard et al., 2001). The economic benefit of consumers is that they pay less for the counterfeit goods than their originals, which tolerates their standardization (Dodge et al., 1996). The Nia and Zaichkowsky studies (2000) suggest that most of the customers are aware of the exclusivity and higher quality of the real product, this example will not affect their willingness to buy a first product instead of a counterfeit product and will not reduce the demand for the original.

\subsection{Moral Recognition}

In an ongoing survey of experimental examination exploring the reasons why buyers purchase fake products, Moral Recognition was a leading factor to perform a critical position in fake utilization (Wilcoox et al., 2009). Status claim, Monetary thoughts, oddity chasing, craving and face awareness intrigues others are additionally recorded as variables for the utilization of counterfeits (Cordella et al., 1996; Eissend \& Schucchert-Guler, 2006; Sharma \& Chan, 2011; Wilcoox et al., 2009). Now Moral Recognition, is characterizes as person's understanding of a circumstance as ethical difficulty (Narva'ez \& Rest, 1994) is considered to act as initial phase in the Moral dynamic cycle. Normally it is recognized that for people taking part in Moral Recognition won't continually decipher circumstances as an ethical quandary similarly with similar power under all conditions (Lee et al., 2015). Therefore, the 
topic of what decides the force of an ethical issue during moral recognition must be thought of. As indicated by (Rostankowski \& Velasquez, 1985), Now that individual is bound to perceive circumstance as an ethical difficulty in the event that they see that an activity will present results and there is a decision accessible to be made. Along these lines, in the circumstance of buying extravagance fake items, an individual must have a decision in buying the fake great and recognize that quest for this activity would energize the creation of results. Further, Now this writing is giving an idea that the two given states related to Moral Recognition are closely met, people would decipher this circumstance as an ethical problem contrastingly dependent on an assortment of variables that characterize moral force (Velasquez \& Rostankowski, 1985; jones, 1991).

Significant writing from (Jones 1991) an issue-unexpected form of model of moral dynamic proposes a concise six components to characterize power of an ethical issue also having greatness of results, agreement related to socials and impact probability, worldly quickness, vicinity, and grouping of impact of a given circumstance. An investigation done by (Tsalikis et al., 2008) that further limits these variables distinguishing, Now components are having best effect for deciding power of an ethical issue. Besides, the apparent probability of impact which is portrayed by (Jones, 1991) commonly recognized as factor having the best effect of apparent Moral Forces (Johansen and Selart). The idea considered as the probable factor that individuals will take part within an indecent demonstration (buying fake merchandise) and this activity will create certain negative results as visualized by individual (Loe et al., 2000). Circumstance subordinate, the other two remaining components that incredibly sway apparent Moral power of an ethical difficulty incorporate size of outcome and fleeting promptness. With regards to the ethical quality of buying extravagance fake products, size of outcome considers the general result which emerges from the demonstration of buying these things (Tsalikis et al., 2008). Consequently, the more noteworthy the quantity of individuals influenced by a circumstance or the more prominent the misfortune encountered, the more noteworthy the apparent size of result will be (Brass et al., 1998). Generally speaking, research recommends a point that the higher an individual perceives degree of result through an activity, the more probability it has for an individual to participate in Moral Recognition and to experience an ethical quandary (Tsalikis et al., 2008; Jones, 1991). As to promptness, the idea mirrors this measurement of timespan between right now (acquisition of the fake great) and when the results are relied upon to happen. Further, by having a more extended timeframe before results are acquired, people will see that the normal antagonistic results of the indecent demonstration are more averse to happen which lessens the need to perceive an ethical issue (Jonees, 1991; Seelart \& Johanseen, 2011; Tsaalikis et al., 2008). In the view of aggregates, every components would adjust ethical power of Moral problems for individuals separately relying upon increments and diminishes previously mentioned ideas, Else than that staying consistent. The Moral power could likewise influence a person's recognition of moral issues through ideas of apparent noticeable quality and distinctiveness. Further, moral difficulties which are more unmistakable and evident to purchasers will include less exertion with respect to the person to perceive. Together, these two elements improve the probability of a person to perceive moral situation (Loe et al., 2000; Jones, 1991). 
On the other hand, regarding the factor of Moral Recognition and power of issues related to morality, research proposes, that any individual who doesn't really need to see an ethical quandary in every mentioned circumstances (Brass et al., 1998). For instance, for low power circumstances almost certainly, an individual won't see an ethical quandary even as higher apparent force as defined activity, Now as the probability increases individuals would take part in the process of Moral Reasoning measures. Moreover, when an individual neglects participation to recognize an ethical issue, This form might use various types of dynamic while taking part in the demonstration of buying fake merchandise (Jones, 1991; Tsalisks et al., 2008). In addition, this apparent Moral power related to the circumstance which plays a vital role in moral recognition.

As far as fake buy aim, past investigations likewise show that customers' inner moral commitments, which depend on moral norms, could decrease fake buy aim. This happens in case when individuals having a thinking for higher conditions of Moral Judgement, accordingly using more elevated levels for Moral thinking bringing down fake buy goal while diminishing the event of indecent lead (Valgeirsson \& Furnham, 2007; Christodoulides \& Michaelidou, 2011; Trevino, 1992; Tan, 2002). Also, mentalities regarding lawfulness of fake buying impact fake buy aims (Cordeell et al., 1996; Swinyaard et al., 1990). Moreover, current and previous indicated mentalities for fake buying, style, and for providing social awareness that are indicators of fake buy goal (Shelley \& Marcketti, 2009). Ultimately, Study and research shows how Moral Recognition increases moral concerns of people, in this way impacting counterfeit buy expectation. In light of these discoveries, Now it is foreseen clearly that the presence of Moral Recognition would bring about decreased fake buy expectation.

H1: Moral Recognition has negative relation with Purchase Intention of Counterfeit goods, In a way that an individual that recognize Moral Dilemma will have lower Purchase Intention

\subsection{Moral Reasoning Strategy}

Recently Moral Psychology theories, Moral Reasoning, arises as intuitive Moral Judgment, usually the Post-Hoc structure designed to support the Moral Judgment like with Intuition (Had, 2001). Now, there is moral ambiguity, the inherent ambiguity allows an individual to reach the ethical decision that produces the desired outcome (counterfeit purchase intent) by selecting information to modify their ethical reasoning process (counterfeit purchase intent) accordingly (Dittoo et al., 2009).

Now in order to understand the concept of Moral identity and how it leads Purchase Intentions, it is necessary to consider the relationship between use of moral reasoning strategy and Moral Recognition. Now it is believed that moral recognition and its use in regards of moral reasoning strategies depends on the state of the individual's movement (Jones, 1991). Depending on the situation with vision to support individual to engage in immoral activity, various Moral Reasoning processes (Moral Rationalization and moral Decoupling; Bhaattacharjee et al., 2013) have stated (Li et al., 2015). So uses, when individuals who are trying to find ways to resolve the stress and tension generated by identifying the Moral Dilemma and Moral Reasoning strategy to reduce tension and justify the actions applied (Jones, 1991; Li et al., 2015). In addition, (Jones, 1991) states that Moral Ambiguity as 
increases, individuals need to justify behavior so that as the intensity levels of moral ambiguity increase, more and more moral reasoning strategies are adopted. Therefore, people who recognize the ethics of buying counterfeit products and those who continues to motivates to buy product use Moral Reasoning process to assists Ethical Decisions, while constantly striving to obtain desired results (Bhattaacharjee et al., 2013).

Now, In the case of Fraudulent the Counterfeit goods purchases (where buyer are able to understand the differences between counterfeits \& genuine product; Wideeman et al., 2012), Consumers (Cordell et al.) Must face Motivational conflict $b / w$ economic benefits ethical principles and Hedonic benefits (Valgierson \& Furnheim, 2007). Violation of these ethical principles or withdrawal of benefits can lead to tension or conflict (Eisenhower \& Schuchertg, 2006). Now, to overcome this stress and tension, Some of them might decide not to purchase counterfeit goods, meanwhile other may pursue moral reasoning strategies strongly motivated by profit (Tsang, 2002). The latter is supported by changes in the logical process by changing the moral judgment to suit the outcome which are desired (Ditto et al., 2009).

Since, two ethical consultation strategies affect the purpose of the acquisition or support of the respondent: Moral Rationalization \& Moral Decoupling (Bhattaacharjee et al., 2013). Behavioral Rationalization decreases the misconduct \& often have utilization by consumer in particular situation where knowledge of questions related to behavior and ethics (e.g. sweat shop) having involvement in the desirable behavioral products (Bhattaacharjee et al., 2013). This particular strategy allow consumer to justify fraudulent purchase through decreasing complexity of the legal term in question. In addition, Moral Rationalization often exercised for cases with legal nature and where is unclear, there is possibility for the case in many question which may be deemed to be detrimental immediately, leading to a delayed outcome (McAllister et al., 2006; Shuu et al., 2011). Nevertheless, because behavioral Rationalization considered to have strongly linked to the consumer's perception of his or her behavior, some strategies are more difficult to implement than ethical decoupling (Lee \& Quick, 2015). Implementing ethical decoupling strategy allows the consumer to distinguish illegal activity from product performance (Bhattaacharjee et al., 2013). Through distinguishing good and bad, consumer can comfortably use the moral decoupling as a direct way to obtain fraudulent purchases. While it is much easier to apply the ethical decoupling of people with low and low content, the two processes of behavioral thinking different and distinct. Therefore, it is expected that people will make the most of the moral decoupling in behavioral planning, specially when situations are clear. Now, if one is quick to see certainly the action considered unethical, Moral Decoupling is used to make a difference in moral judgment because it is difficult to minimize strong moral judgment (Bhaattacharjee et al., 2013; Lee \& Quack, 2015). Nevertheless, Situations where apparent virtue does not seems, Moral orders is likely to grow. Moreover, as it is clear that these two processes are different from each other, now enhance understanding is needed to evaluate how these processes actually interact from Bhattacharjee and others (2013) this gives suggestion about people and how they can apply these behaviors simultaneously. 


\subsection{Moral Rationalization}

Moral Rationalization commonly characterized as the psychological cycle which people utilize to recreate improper activities and converting them into less indecent activities (Aquino et al., 2007; Baumeister \& Newman, 1994; Bhattaacharjee et al., 2013; Mcalister et al., 2006; Shu et al., 2011). Consequently, while confronting an ethical difficulty to legitimize a possibly indecent conduct, utilizing a moral rationalization methodology permits a person to disregard moral standards while protecting some similarity to being moral (Tsang, 2002). Buyers are regularly enticed to buy fakes because of their low costs, frequently at the cost of ethical standards (Wiedman et al., 2012). Now at times Moral Reasoning system is probably going to get utilized

From the perspective of moral rationalization, three theories can be utilize three to call various segments of inspirations driving, the thought of why people justify improper practices: intellectual discord, self-attestation, and moral disengagement (Tsang, 2002). To start with, intellectual cacophony is a type of mental distress, happening when one's impression of deliberate practices negate their convictions. Decrease techniques are then delivered to ease this distress (Ellkin \& Leipe, 1986; Eliot \& Deviine, 1994; Festiinger, 1962). The outcome is, choices would be altered. In any case, explicit to Moral Rationalization, numerous individuals would get alter conviction by the addition of amicable components, consequently lessening the significance of cacophonous components, or by rethinking these offensive components to recreate the improper go about as an ethical (Eisend \& Schuchert-Guler, 2006). Secondly, assertion and self-assertion centers around inspiration of individual to provide reaffirmation by themselves and as great as keeping up a positively driven idea to determine irregularities (Tsang, 2002). So the sum-up, The time when people confronted with vague and ambiguous insights, There is a chances that might be inspire psychological discord for the justification of unethical practices into moral practices, though people spurred without anyone else confirmation could concede their bad behaviors and creating reaffirmation for themselves as great sign (Tsang, 2002). Thirdly, the drawings on Moral Disengagement theory, that people spurred for legitimizing indecent conduct by them as a blame evasion (Tsang, 2002). Moral Disengagement is often characterized as a embracing assorted Moral thinking methodologies for legitimizing or to pardon shameless lead (Bandura, 1999; Bandura et al., 1996; Bhattacharjee et al., 2013). Researchers interfaces mental distress to authorizing self components with respect to Moral guidelines. As such, people should shun carrying on in manners which abuse their ethical norms and rather performing positive actions to maintain positive mental self portrait; else, that can cause them to encounter self-judgment (Bandura, 1991, 1999; Bandura et al., 1996). People could likewise keep away from such blame or self-judgment through specific initiation \& moral separation of ethical control factor (Bandura, 1991, 1999; Bandura et al., 1996; Chen et al., 2015; Shu et al., 2011). In nutshell, the cognitive dissonance and self-affirmation theory cannot totally represent all moral rationalization wonders, consequently, these speculations don't give the best clarification to a person's utilization of moral rationalization. Conversely, moral disengagement presents complete and closely created the theory of Moral Rationalization (Tsang, 2002). 
Fake extravagance product represent an ethical quandary for buyers who have built up a passionate connection to the first known brand (Hennings et al., 2015). Having consideration that buyers are worried regarding carrying on Morally \& consenting to regularly share standards, for example, licensed innovation right assurance, we can deduce that customers needing to buy fake extravagance brands need to limit the hole between their ethical norms and genuine buy goal (Aquino \& Reed, 2002; Shu et al., 2011). Generally speaking, individual is more viable in persuading them to conduct doesn't disregard moral norms, for this accommodates such clashes got misalignments for their convictions \& activities (Bhattacharjee et al., 2013; Hanzaee \& Jalalian, 2012; Tsang, 2002). All things considered, customers can help in their capacities to forgo any self-endorse forced by the blame of counterfeit utilization by withdrawing from self-judgment. People will utilize diverse moral rationalization procedures to reconsider their improper practices as less corrupt subsequent to experiencing a cycle of Moral thinking (e.g. "Purchasing of fakes extravagance brand is not awful as portion of the other loathsome things individuals do"; "It is alright to get a couple of fakes of extravagance brands, since it doesn't generally do much harm"). At the end of the day, this examination includes Moral Rationalization particularly as a class thinking systems for Moral Disengagement. for instances related to non-deceptive fake buying, Recognition of antagonistic Moral outcomes could vary individuals to individuals simultaneously choice to choice. Moral Recognition prompts a higher degree of blame shirking \& high number of endeavors for application of adapting systems, for example, moral rationalization (Eisend \& Schuchert-Gu“ler, 2006). In the event that buyers perceive a total ethically wrong idea to buy fakes, this results in less inclination to receive Moral Rationalization strategies. Interestingly, at times when profound quality remain uncertain, as it gets simpler in order to receive the Moral Rationalization system. Agreeing with the rationale, more people see fake buying to be an ethical issue, the less people would experience an ethical problem, and the more uncertain a moral rationalization technique will be received.

H2: Moral Recognition has negatively related to Moral Rationalization, in a way that increases Moral Recognition which is associated with decreased Moral Rationalization.

Moral Rationalization people to persuade their fake buy goal stays reliable with their ethical principles. At the point when people experience obscure Social assessment \& Moral principles falsifying and also with inclination toward buying, Now this inclination twists their understandings. People don't go searching for proof of their culpability or the unfriendly impacts of fake buying, yet endeavor to evade blame or humiliation with the capacity to excuse the equivocal conduct (Ditto et al., 2009; Kim \& Johnson, 2014). In views of the feeble requirement of counter fake laws \& vagueness of the meaning of fake (Wanjau \& Muthiani, 2012), people can without much of a stretch utilize the moral rationalization technique to help their buying expectation. Thusly, the moral rationalization methodology prompts an expanded fake buy expectation.

H3: Moral rationalization is positively related to counterfeit purchase intentions, such that increased moral rationalization is associated with increased counterfeit purchase intentions.

Moral rationalization lessens the strain between wanted advantages and people's ethical 
principles by remaking the demonstration of fake buying with the goal that an ideal self serving moral judgment can be reached (Wang et al., 2014).

As Moral decisions are made on the basis of some ground that has a purposeful, controlable, and effortful cognizant cycle, comprising some mental actions related to changing data regarding individuals (Bargh, 1994; Galotti, 1989; Musschenga, 2008). In our exploration, purchasers sometimes are bound to get advantage by looking for rebuilding activities they are doing which could be less indecent. In this way, such a judgment is a kind of contemplated induction, looking for a pertinent support for profound quality (including moral defense, indirect language, worthwhile correlation, removal of duty, dispersion of obligation, bending of outcomes, attributes of fault; Bandura et al., 1996), organizing support along with circumstances, and reaching at judgment.

H4: Moral Rationalization has positive relation with Moral Judgment, in a way that increase Moral Rationalization which is associated with increase Moral Judgment.

By taking the perspective of social cognitive theory, for various moral pickles, distinctive Moral principles will get utilized depending the circumstances as opposed to depending on a single type of Ethical standard which can be predictable along with single condition for ethical thinking (Bandura, 1991, 1999; Bandura et al., 1996). On the off chance that people hold positive moral convictions toward fakes, in contrast with the individuals who accept such conduct is improper, they will display higher fake buy goal (Fernandes, 2013; Wilcox et al., 2009). Past examinations, in view of Moral Development theory, is reliably affirmed the higher condition of Moral Judgment prompts lower frequency of Immoral Lead (Fernandes, 2013; Prendergast et al., 2002; Trevino, 1992).

H5: Moral Judgment has positive relation with counterfeit purchase intention, in a way that high Moral judgment is associated with higher counterfeit purchase intention.

\subsection{Moral Decoupling}

The term Moral Decoupling is defiened as psychological method which is chosen to prevent misconduct, thus separating the functional judgment of moral judgments (Bhattacharjee et al.. 2013). Person with a behavioral problem, the person will use a strategy of moral decoupling and therefore not to worry about misconduct. For e.g., to totally avoiding self disicipline, the behavioral retreat strategies eliminates binding behavioral judgments (e.g., fraudulent misconduct) using another set of standard judgement (For Example cannot reject prudent prices).

Nevertheless, people begin to value more and more to buy counterfeit goods, they do not need to use moral restraint in an effort to create less moral stereotypes. Instead, they will be more appreciative of exploiting the decline of morality by distinguishing the morals of immorality using the form of performance related to counterfeits acquisition, like economic limitaion \& total brilliance. In case of fraudulent detection which is obviously considered as Immoral act, it is difficult for eople to break free from employment. However, when morality becomes doubtful it is man-made, and it is easier for them to accept a deteriorating morality. That is, the more people understand that a counterfeit item becomes a behavioral problem, the 
younger people may experience a behavioral problem, so when the strategy is reduced.

H6: Moral Recognition is related to Ethical Decoupling, Now the problem is that it considered as Morally wrong, In case a proper Moral Decoupling strategy might get followed.

Keeping with the above pace, decline in behavior could easily resolves discrepancy between acquired end associated with counterfeits good acquisition and standards of conduct. Now when people are confronted with confusing moral standards, they deliberately differentiate between confusing behavior and moral judgment. As it is, people will simply use a behavioral retreat strategy to support their goal of recovery, the reason it is not deliberately involves in allowing misconduct (Bhattacharjee et al., 2013). Thus, this strategy of Ethical Decoupling will leads toward a fraudulent purchasing intent.

H7: Moral degradation is closely related to fraudulent purchasing intentions, which, when employed, have a greater chance of proving counterfeit purchasing intentions

If the individual gradually receives the benefit of the counterfeit product in the form of evaluation. This issue encourages an individual, in addition to their daily routine (Sharma \& Chan, 2011), in illustrating the benefits of the product. The brands have high quality and even moral advantages (Gentry et al., 2001). Some employers also assume that the choices of the fake brand product are the same and that the initial brand product is largely based on this. Since each product is on the same path, and also because of saving, and for benefit support (Lee, 2009) Consumers completely understand the goods in their own profit and disadvantage analysis, this complete value analysis appears to have been used as a perceived value (Zeithaml, 1988).

The opposite may be investment, time or energy until one of the pieces is reliable. Dealing with the brand with having same impact and throught this impact the client must give importance to the brand. Now this jointly makes shopping for products easier by the wishes and protection. (English, 1991).

As Moral Decoupling, act as a psychological separation method, by selection it changes the way in which a personal view counterfeits getting to get related with the performance.Now when people going to adopt this strategy, they would concentrate on social gaps and edges that are images, status, consumptions etc.) \& economic edge (i.e. Perceived fashion contents, Physical Looks, Performances and scarcities, etc.) for the acquisitions (Chen et al., 2015; Eisend \& Schuchert-Guler, 2006; dynasty \& Hsieh, 2012).

H8: Moral Decoupling is positively relates with Perceived benefit, in a way that itincreases Ethical Decoupling which is associated with the Increase Perceived benefits through Countefeit purchasing.

Usually when people understand perceived advantage only in terms of performance, they're going to be driven solely to deal with the purposeful or hedonistic options of counterfeits, so satisfying each their conspicuous and sensible desires (Cordell et al., 1996; Eisend \& Schuchert-Guler, 2006; Sharma \& Chan, 2011; Wilcox et al., 2009). 
H9: Perceived Benefit has positive relation with more fake buy Intention.

\subsection{Materialism}

The materialism is also be define in this way by the individual who is interested in acquiring the goods (Belk, 1984). The consumer is intrigued by or not the purchasing of such goods in the context of this joint assessment (Furnham \& Valgeirsson. 2007). By detection, the consumer assessed the product and thus the product stuff the buyer determines that the product is genuine or not. The materialist consumer has the features, the picture and therefore the product look like and is also conscious of the key cause behind the product (Netemeyer et al., 1995). The Materialist consumer is also possessive who are materialistic additional possessives regarding their power in society and want to co-care about their correctness in society were assessed accordingly (Belk, 1985). This is a positive link between the materialist and therefore, the consumer's purpose for sensible can be mutually understood by the previous support for facts (Yoo \& Lee, 2009). The mindset of (Sun et al., 2014) gives additional focus to shopping for a fake commodity to people with a materialist mentality. The materialistic people swing wealth and want to mould the standard of society. All this depends on its standard in society. The three concepts that materialism also endorse are knowledge of things, conservatism and envy (Belk, 1983). These ideas enhance the importance of materialism as well as knowledge about things where the individual is suspect and possessive of goods and services often wishes to show their control over things (Belk, 1982). The physical objects that during this time jointly cover the expertise of such products as the searching experience, etc., the financial advantage such as money, etc. The second concept of conservative thought and low-level reasoning in respect of goods does not discuss matters with others. The lack of donations to help others and provide mutual support and, consequently, the last ideas which support materialism in addition is that envy is a slim mind (Richins \& Town, 1992).

Materialism is defined on the following parameters and basics which are defined here. One of the approaches is to be self-centered, when a person does not share the objects with alternative ones, wishes satisfaction and knowledge of things to explain the attitude of development (Swami et al., 2009). The researchers jointly shows and encourages the enormous method to materialism by researching this (Lu \& Metal, 2010). The principle of conspicuous consumption theory (Veblen, 1899) refers to the client's preference for a costly good, and their commitment to that good is a justification for the moral nature of individuals against the action. These product types, which are purchased, do not influence their materialistic usage as (Mason, 2001), but the reverse is the additional commodity, which specifically identifies that the products are identified in society. Multiple analyses of the nature of materialism are already under way, and these studies are important for our future study (Corneo \& Olivier, 1997). The money and standard place that is set within societies through the condition of economic, however, the shoppers who are concerned about this as a matter of priority are going towards the shopping because they are pretending to be the stigma of the commodity in which the standard of the counterfeit branded products is created by this society. 


\section{Macrothink}

Materialism has a positive moderating effect in the relationship of moral recognition and counterfeit purchase intentions, like we can say that higher the materialism higher will be the positive relation between moral recognition and counterfeit in purchase intentions.

H10: materialism has a positive moderating effect in the relationship of moral recognition and counterfeit purchase intentions, such that higher materialism could lead to more pronounced effect of moral recognition and counterfeit purchase intentions.

Fournier and Richins (1991) found that when they purchase materialistic goods, materialistic consumers feel satisfied. We believe that materialism has a positive impact on counterfeiting because of these results and have put forth the following hypotheses:

H11: Materialism is positively related to increased counterfeit purchase intention.

\subsection{Schematic Diagram}

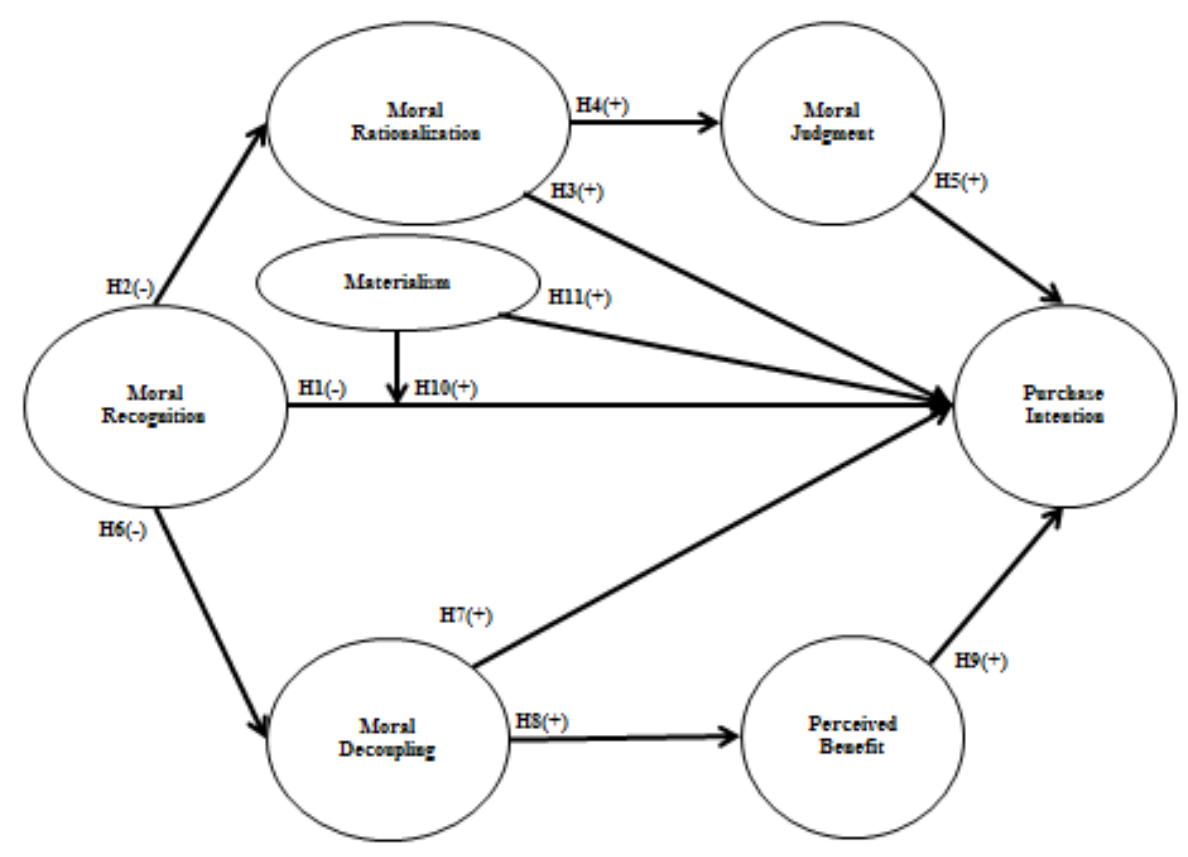

Figure 1. Relation of moral recognition and materialism with purchase intention and others

\section{Methodology}

\subsection{Research Design}

Quantitative Research Method is used in this study. The research implies is descriptive in nature. The collected data is tabulated and tested by structural equation model software called Smart PLS3 and techniques of bootstrapping and algorithms is applied to acquire results. The non-probability convenience sample method was used to collect data and descriptive statistics is mean to analyze individual's opinion in form of their responses of given questionnaire. Structural equation modelling and Confirmatory factor analysis CFA is used for developing inference. 


\subsection{Sampling and Data Collection}

The technique use for sampling is non-profitability convenience for data collection that means to obtain required data from cluster of individuals who are willing and easily accessible. The samples were taken from colleges and universities. The type of data is primary and structured questionnaire was prepared with close ended questions including demographic characteristics. The respondents participate willingly without any financial incentives offer to them

The sample consists of 200 usable respondents out of 230 samples. A proper aligned and organized survey has conducted for the tabulation and collection of information related to research by following the way paved by previous researcher and scholars. In Addition, The questionnaire was disseminated through Internet, Using this medium 60 questionnaire were filled online meanwhile 60 questionnaires were distributed to different consumer in Karachi. Online data via Qualtrics is collected. Approaching respondents is made possible through social-Networking websites, Various forums through Linkedin mailing and offline data is obtained through questionnaire distribution in college and universities. In our study, the consideration is structured survey to achieve more respondents in restricted and constrained timespan.

\subsection{Measures}

There are seven variables used in this study, which are moral recognition, moral rationalization, moral judgment, moral decoupling, perceived benefit, materialism and counterfeit purchase intention. All the variables were measured on five-point likert scale i.e., strongly disagree, disagree, neutral, agree \& strongly agree. All the scales were adopted from previous researches.

\subsubsection{Moral Recognition}

Moral recognition is basically the moral awareness that is negatively associated with counterfeit. The construct was measured by one item scale which adopted from Barnett and Valentine (2004); Valentine and Hollingworth (2011). The question was restricted with five-point likert scale from strongly disagree to strongly agree.

\subsubsection{Moral Rationalization}

The 8 items of moral rationalization were taken from the scale developed by Bandura et al. (1996); Bhattacharjee et al. (2013). Volunteers were provided selected scales to express their thoughts regarding counterfeits purchasing. Sample statements were: 2) It is not a bad thing to buy one or two counterfeits of luxury brands. The Cronbach @ of the scale was 0.924.

\subsubsection{Moral Decoupling}

The measure of the underlying construct was taken from the established work of Bhattacharjee et al. (2013). Respondents were assessed by three item scales to justify modal reasoning related to counterfeit purchase intention. Statements involved are: 1) The immoral actions of purchasing counterfeits of luxury brands do not change my assessment of benefits provided by counterfeits. The Cronbach @ was 0.889 and one item was removed. 


\subsubsection{Moral Judgment}

When an individual is facing moral ambiguity, he needs moral judgment regarding the issue he needs to cope with. The five items were taken from an already data pushed literature by Reidenbach and Robin (1990). The given statements for the responses are: 2) it is acceptable for my family to buy counterfeits of luxury brands. The Cronbach @ was 0.880 .

\subsubsection{Perceived Benefit}

The measures of this variable are adopted from Bian and Moutinho (2009) including consumer perceived benefits from counterfeit purchasing. The one of sample statements were given for rating is: 3 ) luxury counterfeits may function well.

\subsubsection{Counterfeit Purchase Intention}

The four items of scale were taken from Chen et al. (2016) and Teng and Laroche (2007) research. Respondents were provided with statements for rating: 1) I would intend to buy counterfeits. The Cronbach @ was 0.728.

\subsubsection{Materialism}

The scale is comprised of 18 items based on three sub dimensions which is developed by Richins and Dawson (1992) to observe the degree of consumer attachment to tangible assets and their importance for consumer as an indicator of success. Six items were taken in this study from previous established literature. Responses were provided with close ended statements like; I admire people who own expensive homes, cars and clothes.

\subsection{Demographics}

\begin{tabular}{|l|l|l|l|}
\hline Variables & Group & Frequency & Percentage \\
\hline \multirow{3}{*}{ Gender } & Female & 61 & 30.5 \\
\cline { 2 - 4 } & Male & 139 & 69.5 \\
\hline \multirow{5}{*}{ Education } & $20-24$ & 70 & 35 \\
\cline { 2 - 4 } & $25-29$ & 100 & 50 \\
\cline { 2 - 4 } & $30-34$ & 40 & 20 \\
\cline { 2 - 4 } & $35-39$ & 5 & 2.5 \\
\cline { 2 - 4 } & Above 40 & 15 & 7.5 \\
\hline & Under graduation & 38 & $19 \%$ \\
\cline { 2 - 4 } & Graduation & 87 & $37.5 \%$ \\
\cline { 2 - 4 } & Post-graduation & 75 & \\
\hline
\end{tabular}

Frequency distribution indicates that $35 \%$ of the respondents are in the age limit of 20-24 years, $50 \%$ of the respondents are of 25-29 years of age, $20 \%$ lies between the age limit of $30-34$ years, $2.5 \%$ respondentse age limit is $35-39$ years, whereas, $7.5 \%$ respondents ${ }^{\text {ee }}$ come under the limit of 40 years and onwards. The above table also indicates the gender of the respondents. $69.5 \%$ of the respondents are male and $30.5 \%$ are female. The respondents under graduation are $19 \%, 43.5 \%$ of them are from graduation background and $37.5 \%$ of 
them are post graduated.

\subsection{Descriptive Analysis}

Table 1. Descriptive analysis of factor

\begin{tabular}{|c|c|c|c|c|c|c|c|}
\hline \multirow{3}{*}{\begin{tabular}{|c|} 
\\
Moral \\
recognition
\end{tabular}} & \multirow{2}{*}{\multicolumn{2}{|c|}{ QUESTIONS }} & \multicolumn{2}{|c|}{\begin{tabular}{|l} 
Descriptive \\
Status
\end{tabular}} & \multicolumn{3}{|c|}{$\begin{array}{l}\text { Confirmatory } \\
\text { Analysis }\end{array}$} \\
\hline & & & \multirow{2}{*}{\begin{tabular}{|l|} 
Mean \\
3.050 \\
\end{tabular}} & \multirow{2}{*}{\begin{tabular}{|l|} 
S.d. \\
1.090
\end{tabular}} & \multirow{2}{*}{\begin{tabular}{|l|}
$\begin{array}{l}\text { Outer } \\
\text { Loading }\end{array}$ \\
1.000
\end{tabular}} & \multirow{2}{*}{\begin{tabular}{|l|} 
T \\
Stats \\
100 \\
\end{tabular}} & \multirow{2}{*}{$\begin{array}{l}\mathbf{P} \\
\text { Value } \\
0.000\end{array}$} \\
\hline & 1. & $\begin{array}{l}\text { Counterfeit purchasing actions } \\
\text { involved a moral issue. }\end{array}$ & & & & & \\
\hline \multirow{8}{*}{ 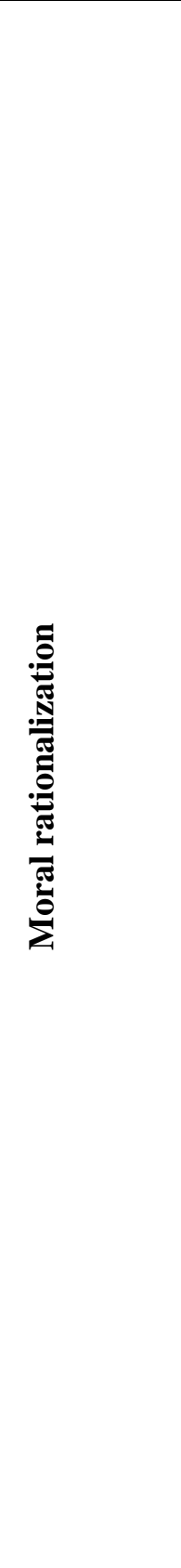 } & 2. & $\begin{array}{l}\text { It is alright to purchase counterfeits } \\
\text { of luxury brands (moral justification) }\end{array}$ & 3.115 & 1.132 & 0.918 & 102.772 & 0.000 \\
\hline & 3. & $\begin{array}{l}\text { It is not a bad thing to buy one or two } \\
\text { counterfeits of luxury brands } \\
\text { (euphemistic language). }\end{array}$ & 3.220 & 1.059 & 0.964 & 256.441 & 0.000 \\
\hline & 4. & $\begin{array}{l}\text { Purchasing luxury brand counterfeits } \\
\text { is not as bad as some of the other } \\
\text { horrible things people do } \\
\text { (advantageous comparison). }\end{array}$ & 3.540 & 0.958 & 0.573 & 7.125 & 0.000 \\
\hline & 5. & $\begin{array}{l}\text { People should not be at fault for } \\
\text { purchasing counterfeits of luxury } \\
\text { brands because of the convenience of } \\
\text { such behavior in recent society } \\
\text { (displacement of responsibility). }\end{array}$ & 3.245 & 1.056 & 0.486 & 4.743 & 0.000 \\
\hline & 6. & $\begin{array}{l}\text { People should not be at fault for } \\
\text { purchasing counterfeits of luxury } \\
\text { brands when so many other people do } \\
\text { it (diffusion of responsibility). }\end{array}$ & 3.320 & 1.062 & 0.739 & 16.709 & 0.000 \\
\hline & 7. & $\begin{array}{l}\text { It is unfair to blame such purchasing } \\
\text { behaviors because it is probably the } \\
\text { fault of business environments } \\
\text { around us (displacement of } \\
\text { responsibility). }\end{array}$ & 3.515 & 1.104 & 0.940 & 138.456 & 0.000 \\
\hline & 8. & $\begin{array}{l}\text { It is okay to buy one or two } \\
\text { counterfeits of luxury brands because } \\
\text { it does not really do much harm } \\
\text { (distortion of consequences). }\end{array}$ & 3.325 & 1.109 & 0.903 & 57.715 & 0.000 \\
\hline & 9. & $\begin{array}{l}\text { It is not our fault to buy counterfeits } \\
\text { of luxury brands because the price of } \\
\text { authentic brands is too high } \\
\text { (attribution of blame). }\end{array}$ & 3.800 & 1.058 & 0.933 & 100.529 & 0.000 \\
\hline
\end{tabular}




\begin{tabular}{|c|c|c|c|c|c|c|c|}
\hline \multirow{2}{*}{ 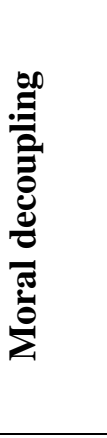 } & 10. & $\begin{array}{l}\text { The immoral actions of purchasing } \\
\text { counterfeits of luxury brands do not } \\
\text { change my assessment of benefits } \\
\text { provided by counterfeits. }\end{array}$ & 3.145 & 0.997 & 0.951 & 195.043 & 0.000 \\
\hline & 11. & $\begin{array}{l}\text { Perceived benefits should remain } \\
\text { separate from judgments of morality } \\
\text { towards purchasing counterfeits of } \\
\text { luxury brands. }\end{array}$ & 3.570 & 0.875 & 0.946 & 181.160 & 0.000 \\
\hline \multirow{5}{*}{ 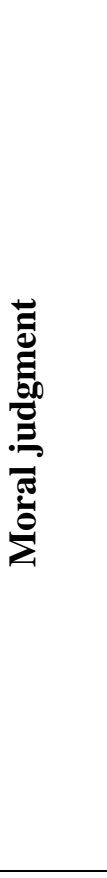 } & 12. & $\begin{array}{l}\text { It is morally right to purchase } \\
\text { counterfeits of luxury brands (moral } \\
\text { equity). }\end{array}$ & 3.290 & 1.156 & 0.409 & 8.317 & 0.000 \\
\hline & 13. & $\begin{array}{l}\text { It is acceptable for my family to } \\
\text { purchase counterfeits of luxury } \\
\text { brands (moral equity) }\end{array}$ & 3.225 & 1.164 & 0.921 & 86.387 & 0.000 \\
\hline & 14. & $\begin{array}{l}\text { It is traditionally acceptable to } \\
\text { purchase counterfeits of luxury } \\
\text { brands (moral relativism). }\end{array}$ & 2.875 & 1.077 & 0.889 & 62.755 & 0.000 \\
\hline & 15. & $\begin{array}{l}\text { It is culturally acceptable to purchase } \\
\text { counterfeits of luxury brands (moral } \\
\text { relativism). }\end{array}$ & 3.155 & 1.068 & 0.937 & 131.076 & 0.000 \\
\hline & 16. & $\begin{array}{l}\text { It is tacitly promised to purchase } \\
\text { counterfeits of luxury brands in } \\
\text { recent business environments (moral } \\
\text { contractualism). }\end{array}$ & 3.260 & 1.078 & 0.920 & 122.712 & 0.000 \\
\hline \multirow{3}{*}{ 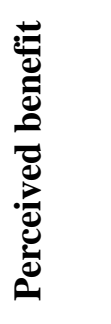 } & 17. & $\begin{array}{l}\text { The quality and price of luxury } \\
\text { counterfeit. }\end{array}$ & 3.260 & 1.006 & 0.962 & 175.988 & 0.000 \\
\hline & 18. & $\begin{array}{l}\text { Luxury counterfeits can bring you } \\
\text { prestige. }\end{array}$ & 3.375 & 1.111 & 0.843 & 33.557 & 0.000 \\
\hline & 19. & $\begin{array}{l}\text { Luxury counterfeits may function } \\
\text { well. }\end{array}$ & 3.290 & 1.061 & 0.355 & 3.000 & 0.003 \\
\hline \multirow{4}{*}{ 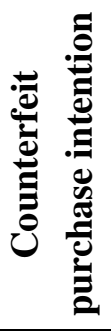 } & 20. & I would intend to buy counterfeits. & 3.105 & 1.193 & 0.849 & 37.862 & 0.000 \\
\hline & 21. & $\begin{array}{l}\text { I would absolutely consider buying } \\
\text { counterfeits. }\end{array}$ & 3.075 & 1.113 & 0.946 & 181.123 & 0.000 \\
\hline & 22. & I would expect to buy counterfeits. & 3.155 & 1.136 & 0.970 & 284.976 & 0.000 \\
\hline & 23. & $\begin{array}{l}\text { I would absolutely plan to buy } \\
\text { counterfeits. }\end{array}$ & 3.180 & 1.112 & 0.064 & 0.496 & 0.620 \\
\hline \multirow{3}{*}{ 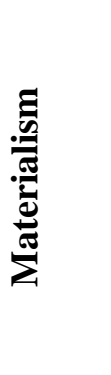 } & 24. & $\begin{array}{l}\text { I admire people who own expensive } \\
\text { homes, cars and clothes. }\end{array}$ & 3.200 & 1.229 & 0.917 & 117.400 & 0.000 \\
\hline & 25. & $\begin{array}{l}\text { Some of the most important } \\
\text { achievements in life include } \\
\text { acquiring material } \\
\text { Possessions }\end{array}$ & 3.150 & 1.174 & 0.907 & 118.353 & 0.000 \\
\hline & 26. & I do not place much emphasis on the & 3.155 & 1.123 & 0.945 & 121.493 & 0.000 \\
\hline
\end{tabular}




\begin{tabular}{|l|l|l|l|l|l|l|l|}
\hline & $\begin{array}{l}\text { amount of material objects people } \\
\text { own as a sign of success. }\end{array}$ & & & & & \\
\cline { 2 - 7 } & 27. & $\begin{array}{l}\text { The things I own say a lot about how } \\
\text { well I am doing in life. }\end{array}$ & 3.515 & 1.249 & 0.901 & 68.995 & 0.000 \\
\hline 28. & $\begin{array}{l}\text { I like to own things that impress } \\
\text { people. }\end{array}$ & 2.820 & 1.161 & 0.856 & 43.533 & 0.000 \\
\hline 29. & $\begin{array}{l}\text { I do not pay much attention to the } \\
\text { material objects other people own. }\end{array}$ & 3.475 & 1.323 & 0.814 & 36.287 & 0.000 \\
\hline
\end{tabular}

The mean value of one item of moral recognition in descriptive statistics table 3.050 and its deviation is 1.090. Moral rationalization with 8 items with mean value ranges from 3.115 to 3.800 having deviation ranges from 0.958 to 1.132 which means that the data is not dispersed and close to the mean value. The overall mean value of moral rationalization is 3.457 which is average and suggests that responses are closely related to 'agree' in five-point likert scale. The mean value of two items of moral decoupling ranges from 3.145 to 3.570 with deviation from 0.875 to 0.997 . The overall mean value of moral decoupling is 3.357 which is above average and indicates that responses support 'agree' in five-point likert scale. Moral judgment with 5 items having mean value lies between 2.875 to 3.290 alongside standard deviation from 1.068 to 1.164 . The overall mean value of moral judgment is 3.082 which shows that responses are around 'neutral' scale. The four items of Perceived benefit with mean value lies between 3.260 to 3.375 with deviation from 1.006 to 1.111 . The overall value of perceived benefit is 3.317 which tells that responses are close to the 'agree' scale. The four items counterfeit purchase intention with mean value ranges from 3.075 to 3.180 having deviation from 1.112 to 1.193 shows dispersed data. The overall mean value of CPI is 3.127 which indicates that responses are slightly moving from 'neutral to agree' in five-point likert scale. The six items of Materialism with mean value ranges from 2.820 to 3.515 having stated deviation from 1.161 to 1.323 . The overall mean of materialism is 3.167 that suggests responses are moving around ' neutral to agree' scale.

Factors loading can be considered as coefficient correlation of each construct with the underlying latent factor which shows the variance explained by the variable on that specific factor. Generally, factor loading more with value more than 0.5 are considered significant and loading lower than 0.5 indicate weak bond and should be discarded from the model. In the table of confirmatory factor analysis factor loading of all constructs except few ones are more than 0.5 and support strong loadings. Some lower factor loadings including one item in moral rationalization with values 0.496 , one item in moral judgment value 0.409 , and one item in perceived benefit with value 0.355 indicate weak bond between the items and their corresponding latent constructs. One item in counterfeit purchase intention with loading value 0.064 shows very weak bond and should not be considered. T statistics is used to measure the variance between the mean of two groups. The higher the $t$ values, the more favorable chances for alternate hypothesis to be accepted and null hypothesis to be rejected since all the constructs having $t$ values more than 1.96 and $\mathrm{p}$ values are less than .05 shows significance of the model expect only one item in CPI having $t$ value 0.496 and $p$ value $>.05$ that is 0.620 is 


\section{Macrothink}

insignificant.

\subsection{Structure Equation Modeling}

For testing of the study hypothesis, here the equation (SEM) Model has been used and the testing has gone through Smart PLS software. In addition, For the test of Direct and Indirect effects all components of test were performed. The application of the equation (SEM) Model is considered as the leading model used under various methods and models for the retrieval (Barron and Kenny, 1986). Is used to test the structural relationship of exogenous and endogenous among each other this also includes multivariate and material analysis. In addition, The equality of the objectives of going back to defining each structure for the assessment of cause and effect relationships meanwhile all the elements in the casual image can reflect their cause and effect in timely manner. Accordingly, the concept of this model which properly ensures the utilization of bootstrapping process that is considered appropriate for large and sample sizes and does not requires any kind of indirect effects (Hayes, 2013). For consideration of all indirect and direct effects, The process used is called bootstrapping (Bolger \& Shrout, 2002).

\section{Measurement Model:}

Table shows results of measurement model.

Table 2. Measurment model of variables

\begin{tabular}{|c|c|c|c|c|c|}
\hline \multicolumn{6}{|l|}{ Measurement Model } \\
\hline Variables & Items & Loadings & $\begin{array}{l}\text { Cronbach's } \\
\text { Alpha } \\
\end{array}$ & $\begin{array}{l}\text { Composite } \\
\text { Reliability } \\
\end{array}$ & $\begin{array}{l}\text { Average Variance } \\
\text { Extracted (AVE) }\end{array}$ \\
\hline \multirow{4}{*}{ Purchase Intention } & CPI1 & 0.849 & \multirow{4}{*}{0.728} & \multirow{4}{*}{0.848} & \multirow{4}{*}{0.640} \\
\hline & CPI2 & 0.946 & & & \\
\hline & CPI3 & 0.97 & & & \\
\hline & CPI4 & 0.064 & & & \\
\hline \multirow{6}{*}{ Materialism } & MAT1 & 0.917 & \multirow{6}{*}{0.948} & \multirow{6}{*}{0.958} & \multirow{6}{*}{0.794} \\
\hline & MAT2 & 0.907 & & & \\
\hline & MAT3 & 0.945 & & & \\
\hline & MAT4 & 0.901 & & & \\
\hline & MAT5 & 0.856 & & & \\
\hline & MAT6 & 0.814 & & & \\
\hline \multirow{8}{*}{ Moral Rationalization } & MORAT1 & 0.918 & \multirow{8}{*}{0.924} & \multirow{8}{*}{0.942} & \multirow{8}{*}{0.682} \\
\hline & MORAT2 & 0.964 & & & \\
\hline & MORAT3 & 0.573 & & & \\
\hline & MORAT4 & 0.486 & & & \\
\hline & MORAT5 & 0.739 & & & \\
\hline & MORAT6 & 0.94 & & & \\
\hline & MORAT7 & 0.903 & & & \\
\hline & MORAT8 & 0.933 & & & \\
\hline
\end{tabular}




\begin{tabular}{llllll}
\hline Moral Decoupling & MORDEC1 & 0.951 & 0.889 & 0.947 & 0.900 \\
Moral Recognition & MORDEC2 & 0.946 & & & \\
& MOREC1 & 1.000 & 1.000 & 1.000 & 1.000 \\
& MORJU1 & 0.409 & & & \\
Moral Judgment & MORJU2 & 0.921 & & & \\
& MORJU3 & 0.889 & 0.880 & 0.919 & 0.706 \\
& MORJU4 & 0.937 & & & \\
& MORJU5 & 0.92 & & & \\
Perceived Benefit & PERCE1 & 0.962 & & & \\
& PERCE2 & 0.843 & 0.596 & 0.791 & \\
\hline
\end{tabular}

In the above table it has a recommended threshold values must be greater than 0.70 and should not be less than 0.40 so that it can be acceptable. The values between this range can be accepted based on convergent validity (Joe, Christian, \& Marko, 2011). The table has factor named purchase intention that has 4 items and highest value is (0.97) and lowest value is (0.064). The second factor is materialism that has 6 items and highest value is (0.945) and lowest value is $(0.814)$. The third factor is moral rationalization that has 8 items and highest value is (0.964) and lowest value is (0.573). The fourth factor is moral decoupling that has 2 items and highest values is (0.951) and lowest is (0.946). The fifth factor is moral recognition that has only 1 item and its value is (1.00). The sixth factor is moral judgment that has 5 items and highest value is (0.937) and lowest is (0.409). The seventh factor is perceived benefit that has 3 items and highest value is (0.962). In addition, this table has values of CR and AVE. The threshold given by Hair Jr, Sarstedt, Hopkins, and Kuppelwieser (2014) for CR is 0.70 and for AVE is 0.50. Thus, this table has achieved all the requirements and has achieved measurement model.

\section{Cross Loading}

Table shows results of cross loadings.

Table 3. Crossloading

\begin{tabular}{llllllll}
\hline Cross loading & \multicolumn{7}{l}{ Morchase } \\
& $\begin{array}{l}\text { Intention } \\
\text { Materialism }\end{array}$ & $\begin{array}{l}\text { Moral } \\
\text { RationalizationDecoupling Recognition Judgment }\end{array}$ & $\begin{array}{c}\text { Moral } \\
\text { Benefit }\end{array}$ \\
\hline CPI1 & $\mathbf{0 . 8 4 9}$ & 0.678 & 0.735 & 0.695 & -0.573 & 0.724 & 0.663 \\
CPI2 & $\mathbf{0 . 9 4 6}$ & 0.947 & 0.928 & 0.952 & -0.415 & 0.956 & 0.935 \\
CPI3 & $\mathbf{0 . 9 7 0}$ & 0.939 & 0.917 & 0.908 & -0.459 & 0.923 & 0.898 \\
CPI4 & $\mathbf{0 . 0 6 4}$ & 0.151 & -0.014 & 0.010 & 0.030 & 0.105 & 0.065 \\
MAT1 & 0.929 & $\mathbf{0 . 9 1 7}$ & 0.898 & 0.889 & -0.526 & 0.916 & 0.867 \\
MAT2 & 0.870 & $\mathbf{0 . 9 0 7}$ & 0.816 & 0.847 & -0.389 & 0.902 & 0.843 \\
MAT3 & 0.881 & $\mathbf{0 . 9 4 5}$ & 0.886 & 0.909 & -0.354 & 0.908 & 0.907 \\
\hline
\end{tabular}




\begin{tabular}{|c|c|c|c|c|c|c|c|}
\hline MAT4 & 0.796 & 0.901 & 0.862 & 0.828 & -0.346 & 0.857 & 0.879 \\
\hline MAT5 & 0.802 & 0.856 & 0.789 & 0.789 & -0.214 & 0.822 & 0.798 \\
\hline MAT6 & 0.718 & 0.814 & 0.798 & 0.770 & -0.277 & 0.755 & 0.768 \\
\hline MORAT1 & 0.925 & 0.923 & 0.918 & 0.917 & -0.495 & 0.933 & 0.891 \\
\hline MORAT2 & 0.925 & 0.940 & 0.964 & 0.943 & -0.456 & 0.957 & 0.933 \\
\hline MORAT3 & 0.436 & 0.483 & 0.573 & 0.542 & -0.141 & 0.444 & 0.521 \\
\hline MORAT4 & 0.484 & 0.529 & 0.486 & 0.517 & -0.111 & 0.565 & 0.510 \\
\hline MORAT5 & 0.689 & 0.596 & 0.739 & 0.637 & -0.515 & 0.591 & 0.631 \\
\hline MORAT6 & 0.866 & 0.895 & 0.940 & 0.919 & -0.408 & 0.875 & 0.901 \\
\hline MORAT7 & 0.837 & 0.832 & 0.903 & 0.838 & -0.324 & 0.835 & 0.839 \\
\hline MORAT8 & 0.829 & 0.873 & 0.933 & 0.899 & -0.382 & 0.844 & 0.887 \\
\hline MORDEC1 & 10.907 & 0.907 & 0.918 & 0.951 & -0.435 & 0.914 & 0.904 \\
\hline MORDEC2 & 20.856 & 0.882 & 0.909 & 0.946 & -0.334 & 0.872 & 0.901 \\
\hline MOREC1 & -0.511 & -0.400 & -0.451 & -0.407 & 1.000 & -0.476 & -0.347 \\
\hline MORJU1 & 0.428 & 0.377 & 0.281 & 0.344 & -0.357 & 0.409 & 0.284 \\
\hline MORJU2 & 0.876 & 0.888 & 0.904 & 0.863 & -0.549 & 0.921 & 0.837 \\
\hline MORJU3 & 0.815 & 0.862 & 0.827 & 0.835 & -0.199 & 0.889 & 0.859 \\
\hline MORJU4 & 0.920 & 0.910 & 0.901 & 0.917 & -0.483 & 0.937 & 0.887 \\
\hline MORJU5 & 0.850 & 0.898 & 0.863 & 0.856 & -0.432 & 0.920 & 0.897 \\
\hline PERCE1 & 0.885 & 0.934 & 0.928 & 0.934 & -0.372 & 0.924 & 0.962 \\
\hline PERCE2 & 0.775 & 0.783 & 0.806 & 0.781 & -0.317 & 0.764 & 0.843 \\
\hline PERCE3 & 0.284 & 0.314 & 0.275 & 0.337 & 0.048 & 0.335 & 0.355 \\
\hline
\end{tabular}

The above table has a recommended threshold that the values in horizontal of each factor must have higher value in comparison to values in other factors (Hair, Christian, \& Marko, 2011). Therefore, this table has showed that discriminant validity has been achieved using cross loadings.

\section{Discriminant Validity}

\section{Fornell and Larcker}

Table has provided results of Fornell and Larcker.

Table 4. Fornell-Larcker Criterion

\begin{tabular}{|c|c|c|c|c|c|c|c|}
\hline \multicolumn{8}{|c|}{ Fornell-Larcker Criterion } \\
\hline & MAT & MORDEC & MORJU & MORAT & MOREC & PERCE & CPI \\
\hline Materialism & 0.891 & & & & & & \\
\hline Moral Decoupling & 0.943 & 0.949 & & & & & \\
\hline Moral Judgment & 0.968 & 0.942 & 0.840 & & & & \\
\hline Moral Rationalization & 0.945 & 0.963 & 0.942 & 0.826 & & & \\
\hline Moral Recognition & -0.400 & -0.407 & -0.476 & -0.451 & 1.000 & & \\
\hline Perceived Benefit & 0.948 & 0.951 & 0.937 & 0.948 & -0.347 & 0.767 & \\
\hline Purchase Intention & 0.939 & 0.930 & 0.949 & 0.936 & -0.511 & 0.912 & $\mathbf{0 . 8 0 0}$ \\
\hline
\end{tabular}




\section{Macrothink}

The above table has a recommended threshold that bold and diagonal values must be higher in their own constructs as compared to the values in other constructs (Fornell \& Larcker, 1981). This table has achieved discriminant validity using Fornell and Larcker.

\section{HTMT Ratio}

Table shows results of HTMT ratio.

Table 5. Heterotrait-Monotrait Ratio (HTMT)

\begin{tabular}{|c|c|c|c|c|c|c|c|}
\hline \multicolumn{8}{|c|}{ Heterotrait-Monotrait Ratio (HTMT) } \\
\hline & MAT & MORDEC & MORJU & MORAT & MOREC & PERCE & CPI \\
\hline \multicolumn{8}{|l|}{ Materialism } \\
\hline Moral Decoupling & 1.027 & & & & & & \\
\hline Moral Judgment & 1.045 & 1.048 & & & & & \\
\hline Moral Rationalization & 1.003 & 1.059 & 1.016 & & & & \\
\hline Moral Recognition & 0.405 & 0.430 & 0.524 & 0.455 & & & \\
\hline Perceived Benefit & 1.095 & 1.143 & 1.110 & 1.103 & 0.387 & & \\
\hline Purchase Intention & 1.055 & 1.058 & 1.116 & 1.041 & 0.558 & 1.106 & \\
\hline
\end{tabular}

The above table has recommendation that values must be less than 0.90 for acceptance (Henseler et al., 2014). Hence, the table has achieved discriminant validity using HTMT ratio.

\subsection{The Structural Model (Inner Model) and Hypotheses Testing}

The structural model helps to understand and analyses the complex relations of the variable, (Jun-Hwa \& Marko, 2019). The structural model was also tested and run on the Smart PLS 3.2.3 (Wende, Ringle, \& Becker, 2015). The given structural model was run through bootstrapping (Tibshirani, 1968; Haenlien \& Kaplan, 2004). The snapshot of the result after running the test is attached below along with the interpretation of the results.

PLS-SEM, the bootstrapping associated with it plays a key role, which provides crucial information for consistency for the factor of approximation. The Sub-tests which are drawn wherever through main model including replacement and the cycle within (Mathews, Hair, \& Sarstedt, 2017). The term Bootstrapping provides strength to the coefficient gauge. In this particular cycle innumerable sub-models drawn from the main model along with replacement (Hair et al., 2016). Ensuring to the execution of bootstrap typical, The Smart PLS represents the t-value, for essential model assessments got using bootstrapping method. All results of route coefficient for given hypothesis are shown up in going with Table. T-Regard is more vital than $1.96(\mathrm{p}<.005)$ represents the basic relationship at $95 \%$ and conviction level $(\alpha=0.05)$. Path demonstrating whether this association among is assessed and latent variables are significant or insignificant. Chart demonstrates as follows 


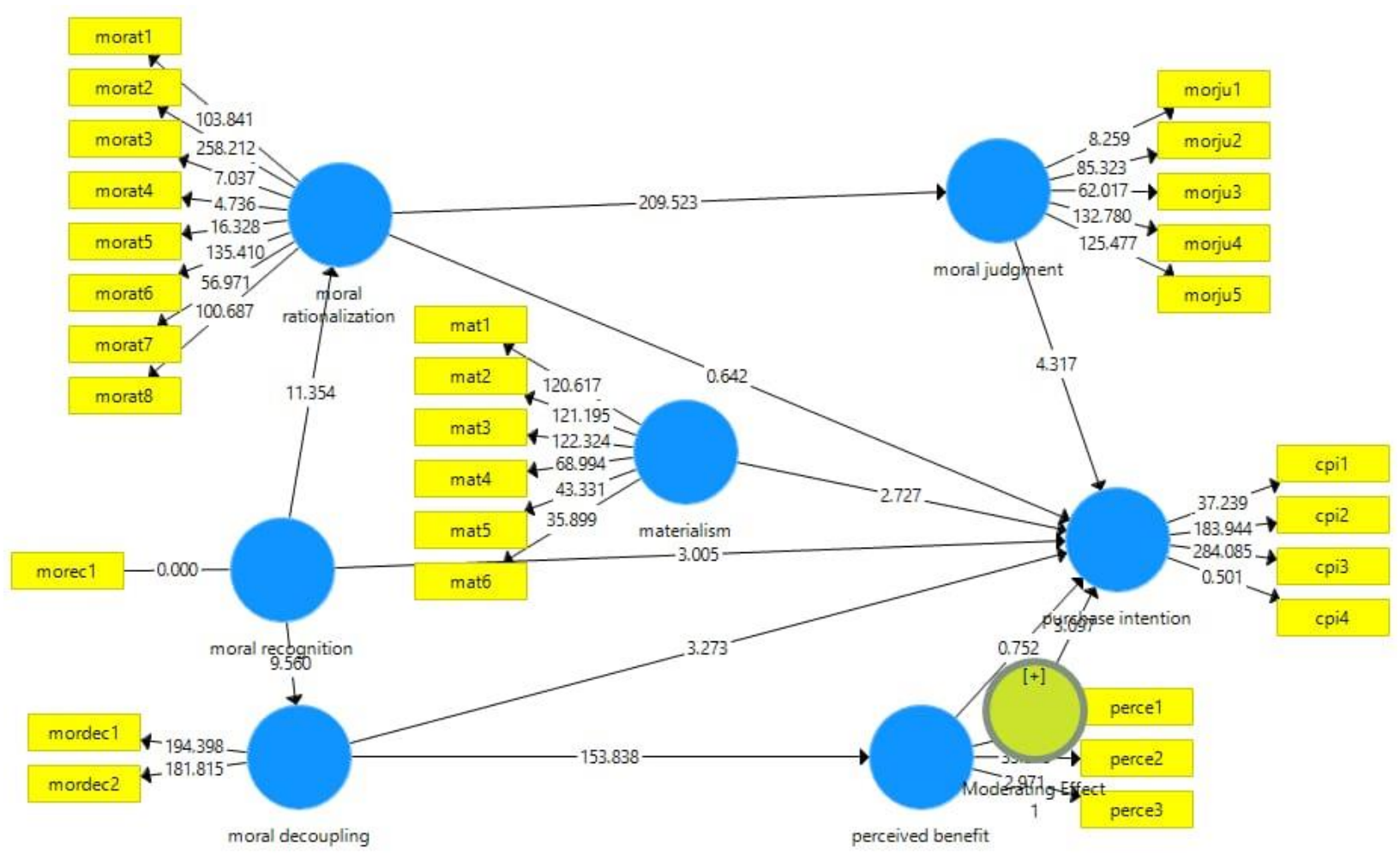

Figure 2. Path analysis

Table shows results of path analysis.

Table 6. Path coefficients of variables

\begin{tabular}{lllll}
\hline Path Coefficients & & & & \\
\hline & EStatment & Std-Dev & T-Stat & Prob. \\
\hline Materialism -> Purchase Intention & 0.267 & 0.099 & 2.702 & 0.007 \\
Moral Decoupling -> Perceived Benefit & 0.951 & 0.006 & 154.675 & 0.000 \\
Moral Decoupling -> Purchase Intention & 0.225 & 0.068 & 3.308 & 0.001 \\
Moral Judgment -> Purchase Intention & 0.369 & 0.082 & 4.492 & 0.000 \\
Moral Rationalization -> Moral Judgment & 0.942 & 0.004 & 209.751 & 0.000 \\
Moral Rationalization -> Purchase Intention & 0.066 & 0.104 & 0.634 & 0.526 \\
Moral Recognition -> Moral Decoupling & -0.407 & 0.043 & 9.454 & 0.000 \\
Moral Recognition -> Moral Rationalization & -0.451 & 0.040 & 11.367 & 0.000 \\
Moral Recognition -> Purchase Intention & -0.077 & 0.026 & 2.970 & 0.003 \\
Perceived Benefit -> Purchase Intention & -0.049 & 0.066 & 0.741 & 0.459 \\
\hline
\end{tabular}

The table shows that materialism $(0.267, \mathrm{p}<0.10)$ has been positive and significant towards purchase intention. The moral decoupling $(0.951, \mathrm{p}<0.10)$ has positively and significantly related with perceived benefit. The moral decoupling $(0.225, \mathrm{p}<0.10)$ has positively and significantly related with purchase intention. The moral judgment $(0.369, \mathrm{p}<0.10)$ has 


\section{Macrothink}

positively and significantly related with purchase intention. The moral rationalization $(0.942$, $\mathrm{p}<0.10)$ has positively and significantly related with moral judgment. The moral rationalization $(0.066, \mathrm{p}>0.10)$ has a positive but insignificant effect towards purchase intention. The moral recognition $(-0.407, \mathrm{p}<0.10)(-0.451, \mathrm{p}<0.10)(-0.077, \mathrm{p}<0.10)$ has a negative and significant effect towards moral decoupling, moral rationalization and purchase intention respectively. The perceived benefit $(-0.049, \mathrm{p}>0.10)$ has a negative and insignificant effect towards purchase intention.

\subsection{Mediation Analysis}

According to the recommendation of Williams, Vandenberg, and Edwards (2009) the intervention or mediation impact can be culminated when the product of the way between Exogenous variable and the mediator (named as path a) and the way between mediator and endogenous variable (named as path b) are significant statistically. (Base ppr). Thus mediation analysis is used to evaluate the cause and effect relationship between an independent and dependent variables through the involvement of third illustrative mediator variable (Hair et al., 2016). The approach of bootstrapping is appropriate for mediation investigation in the light of fact that it makes no supposition about the sampling division of statistics and can be applied to little sample sizes (Hair et al., 2016). In PLS- SEM, to draw the mediation analysis the initial step is to evaluate the direct or immediate impact of independent variables on the endogenous variable, which ought to be significant if mediator is not involved (Zhao, Lynch, \& Chen, 2010).

Below is the table of Specific Indirect Effects showing the mediating effects result.

Table 7. Specific Indirect Effect of the mediating effects result

\begin{tabular}{|l|l|l|l|}
\hline & Est. & T Stat & P Values \\
\hline moral recognition -> moral rationalization -> moral judgment & -0.425 & 11.221 & 0.000 \\
\hline moral recognition -> moral decoupling -> perceived benefit & -0.387 & 9.430 & 0.000 \\
\hline moral recognition -> moral decoupling -> purchase intention & -0.091 & 3.000 & 0.003 \\
\hline moral rationalization -> moral judgment -> purchase intention & 0.347 & 4.488 & 0.000 \\
\hline $\begin{array}{l}\text { moral recognition -> moral rationalization -> moral judgment -> } \\
\text { purchase intention }\end{array}$ & -0.157 & 4.251 & 0.000 \\
\hline
\end{tabular}

From the table of specific indirect effects, there are five apparent moderating relationships examined statistically. The first considers moral judgement dependent on moral recognition and the relationship is believed to be mediated by moral rationalization. The estimated indirect effect is -0.425 that shows that the difference between total effect (when mediator is excluded from the relationship) and direct effect (when mediator is included in the relationship) is a negative number. Meaning, the mediator inclusion effect is bigger than avoiding it. This is found to be statistically significant. The specific indirect effect is found to be significant in case of perceived benefit dependent on moral recognition which is mediated 


\section{Macrothink}

by moral decoupling and also in case of purchase intention dependent on moral recognition considering mediation of moral decoupling. In case of the relationship between purchases intention that is dependent on moral rationalization mediated by moral judgement shows the estimated indirect effect as 0.347. This suggests that total effect is found bigger than the direct effect implying lower influence of mediator in the relationship. The last row in the table presents two mediators including moral rationalization and moral judgement mediating the relationship between purchase intention and moral recognition. The value -0.157 suggests that the mediation effect is significant in explaining the relationship between the dependent and independent variable. This means both the mediators play a key role in the relationship.

\subsection{Moderation Analysis}

Table shows results of moderation effect.

Table 8. Moderation effect

\begin{tabular}{lllll}
\hline Moderation & & & & \\
\hline & E-Statment & Std-Dev & T-Stat & Prob. \\
\hline Moderating Effect 1 -> Purchase Intention & 0.152 & 0.050 & 3.026 & 0.003 \\
\hline
\end{tabular}

The materialism $(0.152, \mathrm{p}<0.10)$ has a positive and significant moderation effect.

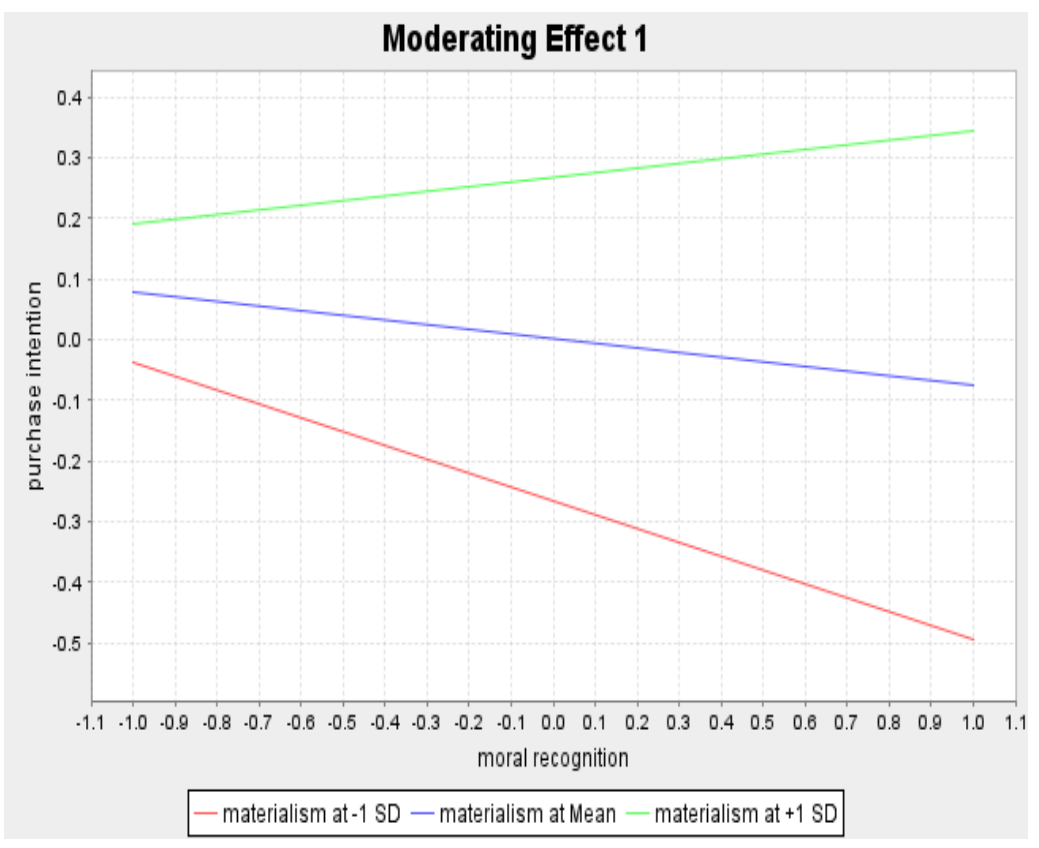

Figure 3. Moderating effect2 
The graph that shows Moderating Effect 1 between purchase intention and moral recognition can be explained in terms theoretical dispositions. The green line shows a moderating effect at $+1 \mathrm{SD}$ of materialism. This suggests that when more variation shows in moral recognition, the purchase intention is positively affected by it and the slope of the curve goes up implying that consumers will be more inclined to buy counterfeits giving less credence to moral recognition. This may not be true for materialism at Mean, as we know that on the average morality should prevail and purchase intention should either remain constant or go down as is visible from the blue line. If we observe the graph at -1SD for moral recognition suggesting more awareness about morality and its recognition, the purchase intentions should go down or should be negatively influenced.

\section{Discussion}

The work done is initially encounters the findings of research previously done on this topic involving the relation of Materialistic approach or materialism and Purchase Intention of Counterfeits. The results are almost equalizing with the base study but there is some area which contradicts when the study based on our local market, that is Moral Rationalization seems to negatively affect Purchase intention through Moral Decoupling, the reason behind that is after getting awareness of the concept of the counterfeit product with the help of moral decoupling consumer feel the action as morally and ethically wrong, this feeling occurs when an individual is going through a thinking process of Moral Judgment resulting in consuming greater degree of moral reasoning, and eventually cause a decrease in the Purchase Intention of Counterfeits .On the other hand it also decrease the immoral conduct (Trevino, 1992; Tan, 2002; Furrnham \& Valgeirson, 2007; Christodooulides \& Micheealiduo, 2011). Furthermore, Moral dilemmas created in the mind of consumers would also tend to get cleared and choices become narrower.

Another variable that is conflicting with the base study is Perceived benefit which has a negative $(-0.049, \mathrm{p}>0.10)$ and insignificant effect on purchase intention unlike the base study, the rationale is, On the local grounds the intention to purchase of consumer is dependent on the moral recognition, however materialism as a moderator can act as a driving force but due to threat of being recognized as a consumer of counterfeit, the purchase intention be prone to decrease. The fact is accepted that individuals who are perceiving benefit in the view of given performance, it would cause more attraction to identify the functionality or consequence-free pleasure of counterfeit product, this eventually fulfills their needs (Cordella et al., 1996; Eisen \& Schucchert-Guler, 2006; Shaarma \& Chaan, 2011; Wiilcox et al., 2009).

The study has successfully met with the base research model, mostly all variable showed accurate behavior, Separate the other two variables mentioned earlier, other variables have shown their effects on purchase intentions. Moral recognition having encompassed by two more variables i.e. Moral Rationalization (MR) and Moral Decoupling (MD) is negatively related with Intention of Purchase, this causes a lower purchase intention. This reason is proved by that attitude toward counterfeit purchasing since it is one parameter to predict counterfeit purchase intention (Shelley \& Marcketti, 2009).

Moral recognition (MR) relates negatively and significantly with moral rationalization (MR), 
such that the increase in Moral Recognition (MR) associates with decreased moral rationalization so both terminologies are closely related to each other. This research depicts that moral recognition enhances the moral questioning of individuals, this effect and persuade the Intention of Purchase toward Counterfeits. On the basis of the above points, It can be predicted easily moral recognition(MR) will cause a decline in purchase intention of counterfeit products that directly means an attempt to avoid guilt or embarrassment of doing something wrong (Kim \& Johnson, 2014; Ditto et al., 2009 ).

Moral Rationalization relates positively and significantly with intention of Purchase of Counterfeits, the increase in Moral rationalization linked with the increased Intention to purchase Counterfeits. Moral Rationalization reduces the hardness of beneficiary and standards of morality in Individual through a revamping act to purchase counterfeit purchase this results in egocentric nature governed moral judgment (Wang et al., 2014).

Moral rationalization relates positively and insignificantly with Moral Judgment, in a way that increase moral rationalization links with increasing Moral Judgment (MJ). According to the theories of Social Cognition, Different innovative model of Morality can also be employed on the basis of situations rather than supported by only one. In the light of current problem statement the type of factors influencing moral standards is only single state of moral reasoning which forms a bridge between thinking and consequences (Bandura et al., 1991, 1996, 1996).

Moral Judgment relates positively and significantly with purchase intention of counterfeit, this results in increase Moral Judgment, a closely linked factor with high counterfeit purchase intention index. The hypothesis creates an effect that embarrassment or realization in immoral conduct, a factor that mediates the relation of Purchase Intentions (Zhao et al., 2010).

Moral recognition(MR)relates negatively and significantly with moral decoupling(MD), in a way that more the dilemma is observe the more it considered morally wrong and the lesser a moral decoupling strategy could be implemented. Individuals can use the strategy that involves Moral Decoupling to support their intent to purchase or Purchase Intention, As it does not includes acceptance of inappropriate behavior (Bhattcharjee et al., 2014).

Moral Decoupling relates positively with counterfeit Purchase Intention and perceived benefit (PB), in a way that whenever it applies Consumer or an individual purchase intention increased. When individuals use this kind of strategy, they have their attention on image, status-quo, social and economic benefits of the object being purchased (Liaao \& Hssieh, 2012; Chen et al., 2015; Esend \& SchuchertGuler, 2006).

Furthermore, the result table shows that Materialism $(0.267, \mathrm{p}<0.10)$ has been positive and significant towards purchase intention which depicts that the consumer having materialism is more likely to have the intention for purchasing counterfeits goods because of the feeling of self-embarrassment because of lack of Moral Judgment and Moral Recognition. According to facts and figure, the ambiguity in perception of product in contrast with original product, could affect the Consumer's nature of materialism, which is more likely to lure consumer purchase it. Moreover, the impact on purchase intentions is moderate in this case but if the product is not recognizable by the people. This research makes support to the exisiting 
literature in two ways. Firstly, with the demonstration of the embarrassment which act as mediator between Materialistic nature and intent to purchase. The materialism often correlates with different characteristics of thought relates with Self-Conscience, Reduces Self-esteem, Status-quo leading towards desires (Kasser, 2016), It is lot different from the embarrassment and uneasiness created due to consideration to purchase Counterfeits which is not experienced. As result showed that Materialism relates positive and significant with purchase Intention $(0.267, \mathrm{p}<0.10)$, this shows that a constant loop effect which this study also confirms with the introduction this factor as mediator, Arguable to process, Researches so far done more effectively to provide better look imposed in this perspective. Secondly,another variable which is equally important as per current research is Moral recognition which relates negatively and insignificantly with Moral decoupling (MD), Moral Rationalization (MR), and Purchase intention (PI) (-0.407, $\mathrm{p}<0.10),(-0.451, \mathrm{p}<0.10),(-0.077$, $\mathrm{p}<0.10)$ therefore Consumer having materialistic nature would buy the counterfeit product due to awareness related to self-embarrassment, self-consciousness. With consumers having concerns about materialism and about the irrespect, appearance status-consciousness, the current researche stablishes a point that perceived Counterfeits can effect the results significantly in the perspective of Purchase intentions for consumer having materialistic nature. Mentioning these research points suggest that detection of counterfeits and counterfeit perceptibility should be two important factors to be considered. Suggested by researches done on this topic (Goldsmith et al., 2012; Richins, 2004), interestingly few insights were gained and in-depth data tabulation might help, as each lower scale measures and provides distinction and motivations in believe in that material possession acquire great importance. In light of our research,this hypothesis is been confirm for all lower scales of materialistic approach. Moreover, the feeling of obligation to provide awareness is necessary for consumers (Nepomucenno \& Larroche, 2015, 2017; Segeev et al., 2015; Sun et al., 2014; Watsson, 2015) found some points through integration of materialism into lower scales.

\section{Conclusion}

The study demonstrates the consumer's ability in the city to use counterfeit goods. To achieve this aim, 200 interviewees in Karachi, the leading city, gather the details. The amount of moral consumption may be an emerging concept for Pakistani client has been seen across the knowledge continuum. The result indicates that in shopping for aim there is a positive and significant connection between materialism and different factors excluding moral recognition. Moral recognition has detrimental and major implications for moral decoupling, moral rationalization and purchased intentions.

The solution for given problem statement implicates the investigation and the impact of materialistic approach on the intention of purchase of Counterfeits. Materialistic approach considered a driving force of consumption. It is defined as the attention that consumers put on goods or products they buy (Belk, 1984, p. 291), This can also be explained as performing immoral conduct to fulfil materialistic desires (Piroog \& Robeerts, 2007; Poonchio \& Arranha, 2008; Waatson, 2003), this is to behave certainly unethical or unprincipled (Munncy \& Eastman, 1998). Moreover, some people having matrialistic approach believes in consuming throught these way sis gives pleasure to them; this signals success in terms of 
material possessions and this will result in a better lifestyle after acquiring possession they are targeting or products (Richiins \& Dawson, 1992). Most of the timematerialism drives the consumption factor,and in consideration of the focus a particular materialist gives to consume, It is not to be surprised about thinking that materialist will be tempt or attracts to have counterfeit Product. Individual who certainly careless about material possession or acquiring desire goods (Havingmoral judgment) have less chances to voluntarily purchase counterfeits goods,Since having those possessions will not seems important to them. Moreover,Incase of lower degree of materialistic approach individual would have less chances to acquire counterfeit goods to made an impression, Since it does not meant to show symbol of success. Keeping in the light of materialistic approachand its interaction with embarrassment, consciousness, Dectection of Counterfeit goods, and perceptibility, the study is aim to help managers in field, marketers and business practitioners to better understands the concept of counterfeits goodpurchase, the study further presents the probablity of embarrassment and self-consciousness tends to refrains or restrict materialist from having possession of counterfeits, Whence counterfeit goods have probablity of getting detect, Other people who practice may take proactive measures, if required. The study also have ethical conclusion. The voluntarily purchase of counterfeit product considered as immoral conduct, Since intentionally or unintentionally it gives benefits to the seller who is selling it illegally by paying few amount in the heads of taxes.During the investigation of materialism as a moderator,A study can be made for future researches that can investigate the standards of product and their purchase in different context.

The present research introduces a definition of morality which remain constant and consistent, By keeping strong association with purchase intention of counterfeits. The study can also represent as less probabilty to purchase counterfeit goods having awarness of the behaviour of immoral conduct. Morality has aggressive or negative connotations for counterfeit utilization of product, however,here a question arise related to universally accepted fact or whether the results are closely link with consumer's moral judgment which remain unchangeable. Taking this perspective,consumer moral judgment.

Secondly, drawing conclusion on the theory of Moral Disengagement, previously study has prove that individual is more likely to rationalized his/her immoral conduct and immoral behaviour by avoiding guilt.

However, earlier researchers were not focused on the cultural aspect of moral recognition and counterfeit product purchase. The relationship perceived can be further conditioned based on consumers' cultural orientation, origin, and regional psychology. In Particular, materialistic culture is often linked withself-penetration to buying and unethical product purchase. Inresponse to this, The modification in Chen's model has been made with the complementary effect of materialisticculture in this regard. Weargue to conclude that the effect of moral recognition, on counterfeit purchases, is stronger in materialistic consumers than consumers having lower materialistic contentin their nature.

Secondly, drawing inference on moral disengagement theory, previous research has shown that individuals are more likely to rationalize their immoral behaviors through guilt avoidance. 
However, previous researchers are not focused on the cultural aspect of moral recognition and counterfeit purchase. The relationship perceived can be further conditioned based on consumers' cultural orientation and regional psychology. Materialistic culture is often linked with self-indulgent to buying and unethical purchase. In response to this, the modification in Chen model has been made with the complementary effect of materialistic culture in this regard. We argue to conclude that the effect of moral recognition, on counterfeit purchases is stronger in materialistic consumers.

\subsection{Policy Implication}

The purchase of counterfeit goods normally considered as immoral conduct Since, the direct benefit is direct toward seller who is selling illegally with the payment of few taxes. It also affects legal and lawful producers, manufacturers, and retailers, moreover it potentially poses a risk to public safety and also affects the customer purchase Intention.

Brand owners, Managers and policymakers needs to get this awareness of prevalence for Counterfeits purchases is not significant due to absence of Moral Recognition. Since, on the external it might seems common but internally it is actually effort of legal and lawful sellers. Study shows that consumer will less likely to attract towards purchasing Counterfeit Goods, If and if they have a strong believe that act of purchasing counterfeitis unethical (Swaamiet al., 2009). Therefore, marketers and policymakers should aware and give awareness to consumers about the harmfulness in the immorality of purchasing counterfeit products.

Policymakers should able to provide proper guidance and awarness of Counterfeiting and its effects on economics and Social market. Moreover the benefits they can acquire, parallel with that,they can causepotential risk to theirself accompained by purchasing counterfeit, Other stakeholders are commonly become victim of this resulting an assertion or pressure that must be placed in a way that Purchasing of Counterfeiting is utterly and absolute selfish act causing social and financial loss to others as well.

\subsection{Limitations and Suggestions}

This article has some limitations, as many studies have. The research findings, however, support its assumptions. The methodological character limits possible test results to draw a hypothesis association instead of working relations between these hypotheses. This study encourages further efforts to explain the circumstances under which moral reasoning strategies are implemented in this particular situation and how materialism affects customers' understanding.

In addition, data was collected in the city of Karachi, hindering its full production in Pakistan so if we are going to consider it in different Pakistani cities like Islamabad, Lahore, and outside Pakistan, add new ideas to this paper. The most critical topic, however, is to look at customer minds.

\section{References}

A. Saeed. (n. d.). Why Counterfeit? A study of purchase ... Qurtuba University. Retrieved from http://www.qurtuba.edu.pk 
Albers-Miller, N. D. (1999). Consumer misbehavior: Why people Buy illicit goods. Journal of Consumer Marketing, 16(3), 273-287.

Aquino, K., \& Reed, A., II. (2002). The self-importance of moral Identity. Journal of Personality and Social Psychology, 83(6), 1423-1440.

Awanis, S., Schlegelmilch, B. B., \& Cui, C. C. (2017). Asia's materialists: Reconciling collectivism and materialism. Journal of International Business Studies, 48, 964-991. https://doi.org/10.1057/s41267-017-0096-6

Bandura, A. (1991). Social cognitive theory of moral thought and action. Handbook of Moral Behavior and Development, 1, 45-103.

Bandura, A. (1999). Moral disengagement in the perpetration of inhumanities. Perspective of Social Psychological Review, 3(3), 193-209. https://doi.org/10.1207/s15327957pspr0303_3

Bandura, A., Barbaranelli, C., Caprara, G. V., \& Pastorelli, C. (1996). Mechanisms of moral disengagement in the exercise of moral agency. Journal of Personality and Social Psychology, 71(2), 364-374. https://doi.org/10.1037/0022-3514.71.2.364

Bargh, J. A. (1994). The four horsemen of automaticity: Intention, awareness, efficiency, and control as separate issues. In R. S. Wyer Jr. \& T. K. Srull (Eds.), Handbook of social cognition (2nd ed., pp. 1-40). Hillsdale, NJ: Erlbaum.

Baron, R. M., \& Kenny, D. A. (1986). The moderator-mediator variable distinction in social psychological research: Conceptual, strategic and statistical considerations. Journal of $\begin{array}{llll}\text { Personality and Social } & \text { Psychology, } & \text { 51(6), }\end{array}$ https://doi.org/10.1037/0022-3514.51.6.1173

Baumeister, R. F., \& Newman, L. S. (1994). Self-regulation of cognitive inference and decision processes. Personality and Social Psychology Bulletin, 20(1), 3-19. https://doi.org/10.1177/0146167294201001

Belk, R. (1985). Materialism: Trait Aspects of Living in the Material World. Journal of Consumer Research, 12(3), 265-280. https://doi.org/10.1086/208515

Belk, R. W. (1983). Worldly possessions: Issues and criticisms. Advances in Consumer Research, 10, 514-519.

Belk, R. W. (1985). Materialism: Trait aspects of living in the material world. Journal of Consumer Research, 12(3), 265-280. https://doi.org/10.1086/208515

Bhattacharjee, A., Berman, J. Z., \& Reed, A., II. (2013). Tip of the hat, wag of the finger: How moral decoupling enables consumers to admire and admonish. Journal of Consumer Research, 39(6), 1167-1184. https://doi.org/10.1086/667786

Bian, X., \& Moutinho, L. (2009). An investigation of determinants of counterfeit purchase consideration. Journal of Business Research, 62(3), 368-378. https://doi.org/10.1016/j.jbusres.2008.05.012 
Bloch, P. H., Bush, R. F., \& Campbell, L. (1993). Consumer "accomplices" in product counterfeiting: A demand side investigation. Journal of Consumer Marketing. https://doi.org/10.1108/07363769310047374

Bodner, R., \& Prelec, D. (2002). Self-signaling and diagnostic utility in everyday decision making. In I. Brocas, \& J. Carillo (Eds.), Collected essays in psychology and economics (pp. 105-123). Oxford, England: Oxford University Press. https://doi.org/10.1098/rstb.2009.0218

Brass, D. J., Butterfield, K. D., \& Skaggs, B. C. (1998). Relationships and unethical behavior: A social network perspective. Academy of Management Review, 23(1), 14-31. https://doi.org/10.2307/259097

Chaudhry, P. E., \& Walsh, M. G. (1996). An assessment of the impact of counterfeiting in international markets: The piracy paradox persists. The Columbia Journal of World Business, 31(3), 34-48.

Chen, J., Teng, L. \& Liao, Y. (2018). Counterfeit Luxuries: Does Moral Reasoning Strategy Influence Consumers' Pursuit of Counterfeits? J. Bus. Ethics, 151, 249-264. https://doi.org/10.1007/s10551-016-3255-y

Chen, J., Teng, L. F., Liu, S. X., \& Zhu, H. H. (2015). Anticipating regret and consumers preferences for counterfeit luxury products. Journal of Business Research, 68(3), 507-515. https://doi.org/10.1016/j.jbusres.2014.09.012

Cordell, V. V., Wongtada, N., \& Kieschnick, R. L., Jr. (1996). Counterfeit purchase intentions: Role of lawfulness attitudes and product traits as determinants. Journal of Business Research, 35(1), 41-53. https://doi.org/10.1016/0148-2963(95)00009-7

Cronan, T. P., \& Al-Rafee, S. (2007). Factors that influence the intention to pirate software and media. Journal of Business Ethics, 78(4), 527-545. https://doi.org/10.1007/s10551-007-9366-8

Davidson, A., Nepomuceno, M. V., \& Laroche, M. (2017). Shame on you: When materialism leads to purchase intentions toward counterfeit products. Journal of Business Ethics, 155, 479-494. https://doi.org/10.1007/s10551-017-3479-5

Ditto, P. H., Pizarro, D. A., \& Tannenbaum, D. (2009). Motivated moral reasoning. Psychology of Learning and Motivation, 50, 307-338. https://doi.org/10.1016/S0079-7421(08)00410-6

Eisend, M., \& Schuchert-Gu“ler, P. (2006). Explaining counterfeit purchases: A review and preview. Academy of Marketing Science Review, 12, 1-26.

Elkin, R. A., \& Leippe, M. R. (1986). Physiological arousal, dissonance, and attitude change: Evidence for a dissonance- arousal link and a "don't remind me" effect. Journal of Personality and Social Psychology, 51(1), 55-65.

Elliot, A. J., \& Devine, P. G. (1994). On the motivational nature of cognitive dissonance: Dissonance as psychological discomfort. Journal of Personality and Social Psychology, 67(3), 382-394. https://doi.org/10.1037/0022-3514.67.3.382

Escalas, J. E., \& Bettman, J. R. (2003). You are what they eat: The influence of reference 
groups on consumer connections to brands. Journal of Consumer Psychology, 13(3), 339-348. https://doi.org/10.1207/S15327663JCP1303_14

Fernandes, C. (2013). Analysis of counterfeit fashion purchase behavior in UAE. Journal of Fashion Marketing and Management, $\quad$ 17(1), 85-97. https://doi.org/10.1108/13612021311305155

Festinger, L. (1962). A theory of cognitive dissonance (3rd ed.). Redwood, CA: Stanford University Press.

Fornell, C., \& Larcker, D. F. (1981). Structural equation models with unobservable variables and measurement error: Algebra and statistics. Journal of Marketing Research, 18(3), 382-388. https://doi.org/10.2307/3150980

Furnham, A., \& Valgeirsson, H. (2007). The effect of life values and materialism on buying counterfeit products. Journal of Socio- Economics, 36(5), 677-685. https://doi.org/10.1016/j.socec.2007.01.004

Gentry, J. W., Putrevu, S., Shultz, C., \& Commuri, S. (2001). How now Ralph Lauren? The separation of brand and product in a counterfeit culture. Advances in Consumer Research, 28, 258-265.

Goldsmith, R. E., Flynn, L. R., \& Clark, R. A. (2012). Materialistic, brand engaged and status consuming consumers and clothing behaviors. Journal of Fashion Marketing and Management: An International Journal, 16(1), 102-119. https://doi.org/10.1108/13612021211203050

Grossman, G. M., \& Shapiro, C. (1988). Foreign counterfeiting of status goods. The Quarterly Journal of Economics, 103(1), 79-100. https://doi.org/10.2307/1882643

Grossman, G. M., \& Shapiro, C. (1988, March). Counterfeit-product trade. The American Economic Review, 78, 59-75.

Haidt, J. (2001). The emotional dog and its rational tail: A social intuitionist approach to moral $\begin{array}{llll}\text { judgment. Psychological } & \text { Review, }\end{array}$ https://doi.org/10.1037/0033-295X.108.4.814

Hair Jr, J. F., Sarstedt, M., Hopkins, L., \& Kuppelwieser, V. G. (2014). Partial least squares structural equation modeling (pls-sem). European Business Review. https://doi.org/10.1108/EBR-10-2013-0128

Hair, J. F., Ringle, C. M., \& Sarstedt, M. (2011). Pls-sem: Indeed a silver bullet. Journal of $\begin{array}{llll}\text { Marketing theory and } \quad \text { Practice, } & 19(2), & 139-152 .\end{array}$ https://doi.org/10.2753/MTP1069-6679190202

Han, Y. J., Nunes, J. C., \& Drèze, X. (2010). Signaling status with luxury goods: The role of brand prominence. Journal of Marketing, 74(4), 15-30. https://doi.org/10.1509/jmkg.74.4.15

Hanzaee, K. H., \& Jalalian, S. (2012). Impact of non-price factors on purchase intention counterfeits. Research Journal of Applied Sciences, Engineering and Technology, 4(18), 3313-3322. 
Hennings, N., Wiedmann, K. P., \& Jung, J. (2015). When the original is beyond reach consumer perception and demand for counterfeit luxury goods in Germany and South Korea. Luxury Research, 1(11), 58-75. https://doi.org/10.1504/LRJ.2015.069803

Henseler, J., Dijkstra, T. K., Sarstedt, M., Ringle, C. M., Diamantopoulos, A., Straub, D.W., ... Calantone, R. J. (2014). Common beliefs and reality about pls: Comments on rönkkö and evermann (2013). Organizational Research Methods, 17(2), 182-209. https://doi.org/10.1177/1094428114526928

Hussain, A., Kofinas, Alexander. K., \& Win, S. (2017). Intention to Purchase Counterfeit Luxury Products: A Comparative Study Between Pakistani and the UK Consumers. Journal of International Consumer Marketing, $\quad$ 29(1), 1-16. https://doi.org/10.1080/08961530.2017.1361881

Jones, T. M. (1991). Ethical decision making by individuals in organizations: An issue-contingent model. Academy of Management Review, 16(2), 366-395. https://doi.org/10.2307/258867

Kalyoncuoglu, S., \& Begum Sahin, B. (2017). Moderating role of materialism in the effect of perceived value on purchase intention of counterfeits of luxury brands. International Journal of Marketing Studies, 9, 4. http://doi.org/10.5539/ijms.v9n4p76

Kapferer, J. N. (1995). Brand confusion: empirical study of a legal concept. Psychology \& Marketing, 12(6), 551-568. https://doi.org/10.1002/mar.4220120607

Kasser, T. (2016). Materialistic values and goals. Annual Review of Psychology, 67, 489-514. https://doi.org/10.1146/annurev-psych-122414-033344

Kim, J. E., \& Johnson, K. K. P. (2014). Shame or pride? The moderating role of self-construal on moral judgments concerning fashion counterfeits. European Journal of Marketing, 48(7/8), 1431-1450. https://doi.org/10.1108/EJM-02-2013-0110

Kohlberg, L. (1969). Stage and sequence: The cognitive-developmental approach to socialization. In D. Goslin (Ed.), Handbook of socialization: Theory and research. New York: Rand McNally.

Lai, K. K. Y., \& Zaichkowsky, J. Y. (1999). Brand imitation: Do the Chinese have different views? Asia Pacific Journal of Management, 16(2), 179-192. https://doi.org/10.1023/A:1015482707900

Lee, J. S., \& Kwak, D. H. (2015). Consumers' responses to public figures' transgression: Moral reasoning strategies and implications for endorsed brands. Journal of Business Ethics. https://doi.org/10.1007/s10551-015-2544-1

Leisen, B., \& Nill, A. (2001). Combating product counterfeiting: An investigation into the likely effectiveness of a demand-oriented approach. In R. Krishnan, \& M. Viswanathan (Eds.), AMA Winter Educators' Conference Proceedings (Vol. 12, pp. 271-277). Chicago: American Marketing Association. 


\section{I Macrothink}

International Journal of Industrial Marketing

ISSN 2162-3066

2021, Vol. 6, No. 1

Liao, C. H., \& Hsieh, I. Y. (2012). Determinants of consumer's willingness to purchase gray-market smartphones. Journal of Business Ethics, 114(3), 409-424. https://doi.org/10.1007/s10551-012-1358-7

Loe, T. W., Ferrell, L., \& Mansfield, P. (2000). A review of empirical studies assessing ethical decision making in business. Journal of Business Ethics, 25(3), 185-204. https://doi.org/10.1023/A:1006083612239

Logsdon, J. M., Thompson, J. K., \& Reid, R. A. (1994). Software piracy: Is it related to level of moral judgment? Journal of Business Ethics, 13(11), 849-857. https://doi.org/10.1007/BF00871698

Lu, L. C., \& Lu, C. J (2010). Moral Philosophy, Materialism and Consumer Ethics: An Exploratory Study in Indonesia. Journal of Business Ethics, 94(2), 193-210. https://doi.org/10.1007/s10551-009-0256-0

Marcketti, S. B., \& Shelley, M. C. (2009). Consumer concern, knowledge and attitude towards counterfeit apparel products. International Journal of Consumer Studies, 33, 327-337. https://doi.org/10.1111/j.1470-6431.2009.00748.x

Mazar, N., Amir, O., \& Ariely, D. (2008). The dishonesty of honest people: A theory of selfconcept maintenance. Journal of Marketing Research, 45(6), 633-644. https://doi.org/10.1509/jmkr.45.6.633

McAlister, A. L., Bandura, A., \& Owen, S. V. (2006). Mechanisms of moral disengagement in support of military force: The impact of September 11. Journal of Social and Clinical Psychology, 25(2), 141-165. https://doi.org/10.1521/jscp.2006.25.2.141

Michaelidou, N., \& Christodoulides, G. (2011). Antecedents of attitude and intention towards counterfeit symbolic and experiential products. Journal of Marketing Management, 27(9-10), 976-991. https://doi.org/10.1080/0267257X.2010.549189

Moore, C. (2015). Moral Disagreement. Current Opinion in Psychology, 6, 199-204. Retrieved from https://www.researchgate.net/publication/281332371_Moral_disengagement

Muncy, J. A., \& Eastman, J. K. (1998). Materialism and consumer ethics: An exploratory study. Journal of Business Ethics, 17(2), 137-145. https://doi.org/10.14207/ejsd.2014.v3n4p125

Mushi, H. M., \& Noor, N. A. M. (2016). Consumer behavior and counterfeit purchase in the Tanzanian Mainland. International Postgraduate Business Journal, 8(1), 49-64.

Nepomuceno, M. V., \& Laroche, M. (2015). The impact of materialism and anti-consumption lifestyles on personal debt and account balances. Journal of Business Research, 68(3), 654-664. https://doi.org/10.1016/j.jbusres.2014.08.006

Nepomuceno, M. V., \& Laroche, M. (2017). When materialists intend to resist consumption: The moderating role of self-control and long-term orientation. Journal of Business Ethics. https://doi.org/10.1007/ s10551-015-2792-0.

Netemeyer, R. G., Burton, S., \& Lichtenstein, D. R. (1995). Trait aspects of vanity: 
Measurement and relevance to consumer behavior. Journal of Consumer Research, 21(4), 612-626. https://doi.org/10.1086/209422

Orth, U. R., Hoffmann, S., \& Nickel, K. (2019). Moral decoupling feels good and makes buying counterfeits easy. Journal of Business Research, 98. 117-125. https://doi.org/10.1016/j.jbusres.2019.01.001

Penz, E., \& Stottinger, B. (2005). Forget the "real" thing-take the copy! An explanatory model for the volitional purchase of counterfeit products. Advances in Consumer Research, 32, 568-575. https://doi.org/10.4236/ijcns.2016.98029

Pirog, S. F., \& Roberts, J. A. (2007). Personality and credit card misuse among college students: The mediating role of impulsiveness. Journal of Marketing Theory and Practice, 15(1), 65-77. https://doi.org/10.2753/MTP1069-6679150105

Ponchio, M. C., \& Aranha, F. (2008). Materialism as a predictor variable of low income consumer behavior when entering into installment plan agreements. Journal of Consumer Behaviour, 7(1), 21-34. https://doi.org/10.1002/cb.234

Ratnasingam, J. K. (2008). The Influence of consumers' moral intensity, perceived risks and moral judgment in purchasing pirated software. Communications of the Ibima, 1, 47-61.

Rest, J. R., \& Narva'ez, D. (1994). Moral development in the professions: Psychology and applied ethics. Hillsdale, NJ: Lawrence Erlbaum Associates.

Richins, M. L. (2004). The material values scale: Measurement properties and development of a short form. Journal of Consumer Research, 31(1), 209-219. https://doi.org/10.1086/383436

Richins, M. L., \& Dawson, S. (1992). A consumer values orientation for materialism and its measurement: Scale Development and Validation. Journal of Consumer Research, 19(Dec), 303-316. https://doi.org/10.1086/209304

Richins, M. L., \& Dawson, S. (1992). A consumer values orientation for materialism and its measurement: Scale development and validation. Journal of Consumer Research, 19(3), 303. https://doi.org/10.1086/209304

Rutland, A., Killen, M., \& Abrams, D. (2010). A new social-cognitive developmental perspective on prejudice the interplay between morality and group identity. Perspectives on Psychological Science, 5(3), 279-291. https://doi.org/10.1177/1745691610369468

Segev, S., Shoham, A., \& Gavish, Y. (2015). A closer look into the materialism construct: The antecedents and consequences of materialism and its three facets. Journal of Consumer Marketing, 32(2), 85-98. https://doi.org/10.1108/JCM-07-2014-1082

Selart, M., \& Johansen, S. T. (2011). Ethical decision making in organizations: The role of leadership stress. Journal of Business Ethics, 99(2), 129-143. https://doi.org/10.1007/s10551-010-0649-0

Sharma, P., \& Chan, R. Y. K. (2011). Counterfeit proneness: Conceptualisation and scale development. Journal of Marketing Management, 27(5-6), 602-626. 
https://doi.org/10.1080/0267257X.2010.489829

Shu, L. L., Gino, F., \& Bazerman, M. H. (2011). Dishonest deed, clear conscience: When cheating leads to moral disengagement and Counterfeit Luxuries: Does Moral Reasoning Strategy Influence motivated forgetting. Perspective of Social Psychology Bulletin, 37(3), 330-349. https://doi.org/10.1177/0146167211398138

Sparks, J. R., \& Pan, Y. (2010). Ethical judgments in business ethics research: Definition, and research agenda. Journal of Business Ethics, 91(3), 405-418. https://doi.org/10.1007/s10551-009-0092-2

Sun, G., D’Alessandro, S., \& Johnson, L. (2014). Traditional culture, political ideologies, materialism and luxury consumption in China. International Journal of Consumer Studies, 38(6), 578-585. https://doi.org/10.1111/ijcs.12117

Swami, V., Chamorro-Premuzic, T., \& Furnham, A. (2009). Faking it: Personality and individual difference predictors of willingness to buy counterfeit goods. The Journal of Socio-Economics, 38(5), 820-825. https://doi.org/10.1016/j.socec.2009.03.014

Swinyard, W. R., Rinne, H., \& Kau, A. K. (1990). The morality of software piracy: A cross-cultural analysis. Journal of Business Ethics, 9(8), 655-664. https://doi.org/10.1007/BF00383392

Tan, B. (2002). Understanding consumer ethical decision making with respect to purchase of pirated software. Journal of Consumer Marketing, 19(2), 96-111. 10.1108/07363760210420531

Trevino, L. K. (1992). Moral reasoning and business ethics: Implications for research, education, and management. Journal of Business Ethics, 11(5), 445-459. https://doi.org/10.1007/BF00870556

Trinh, V. D., \& Phau, I. (2011). The overlooked component in the consumption of counterfeit luxury brands studies: Materialism - A literature review. International Conference on Marketing Studies. https://doi.org/10.7903/cmr.11156

Tsalikis, J., Seaton, B., \& Shepherd, P. (2008). Relative importance measurement of the moral intensity dimensions. Journal of Business Ethics, 80(3), 613-626. https://doi.org/10.1007/s10551-007-9458-5

Velasquez, M. G., \& Rostankowski, C. (1985). Ethics, theory and practice. Englewood Cliffs, NJ: Prentice Hall.

Wang, Y., Stoner, J. L., \& John, D. R. (2014). You're not fooling anyone: How social feedback affects moral disengagement and the purchase of counterfeit luxury products. Advances in Consumer Research, 42, 205.

Watson, D. C. (2015). Materialism and the five-factor model of personality: A facet-level analysis. North American Journal of Psychology, 17(1), 133.

Watson, J. J. (2003). The relationship of materialism to spending tendencies, saving, and debt. 


\section{Macrothink}

Journal of Economic Psychology, 24(6), 723-739. https://doi.org/10.1016/j.joep.2003.06.001

Wiedmann, K. P., Hennigs, N., \& Klarmann, C. (2012). Luxury consumption in the trade-off between genuine and counterfeit goods: What are the consumers' underlying motives and value based drivers? Journal of Brand Management, 19(7), 544-566.

Wilcox, K., Hyeong, M. K., \& Sen, S. (2009, April). Why do consumers buy counterfeit luxury brands. Journal of Marketing Research, 46, 247-259. https://doi.org/10.1509/jmkr.46.2.247

Yoo, B., \& Lee, S. H. (2009). Buy genuine luxury fashion products or counterfeits? Advances in Consumer Research, 36, 280-286.

Zhang, T. (2012). Luxury special: World Luxury Association names top brands in Beijing. Accessed November 24, 2013.

Zhao, X., Lynch, J. G., \& Chen, Q. (2010). Reconsidering Baron and Kenny: Myths and truths about mediation analysis. Journal of Consumer Research, 37(2), 197-206.

\section{Copyright Disclaimer}

Copyright for this article is retained by the author(s), with first publication rights granted to the journal.

This is an open-access article distributed under the terms and conditions of the Creative Commons Attribution license (http://creativecommons.org/licenses/by/3.0/). 